\title{
INFLUÊNCIA DE REGRAS DE CORTE DE INVENTÁRIO NOS RESULTADOS DE ACV DE EDIFICAÇÕES
}

\section{INFLUENCE OF INVENTORY CUTOFF RULES ON WHOLE-BUILDING LCA RESULTS}

\author{
Lizzie Monique Pulgrossi ${ }^{i}$ \\ Universidade Estadual de Campinas, Campinas, SP, Brasil, lizpulgrossi@yahoo.com.br
}

Vanessa Gomes da Silva ii

Universidade Estadual de Campinas, Campinas, SP, Brasil, vangomes@unicamp.br

\begin{abstract}
Resumo
A escassa literatura disponível sobre avaliação do ciclo de vida de edificações (ACVed) aponta a necessidade de reduzir os fluxos considerados. As regras de corte auxiliam a viabilizar a modelagem, mas o efeito de variações na sua aplicação é inexplorado na literatura. O objetivo deste trabalho é investigar a influência da aplicação das duas principais abordagens de corte de inventário utilizadas em ACVed - por massa e energia, indicada pela norma EN 15804, e por subsistema construtivo, como adotado pela certificação LEED v4 - relativamente ao inventário mais completo possível ("best-of-knowledge"). Impactos do berço ao túmulo foram calculados para dois casos. A plataforma SimaPro v8.5/9.0 apoiou a composição dos processos e adaptações da base Ecoinvent. Foram utilizados os métodos CML-IA baseline e CED para avaliação de impacto, e clusterização k-means para prospecção de relações entre categorias ambientais. Enquanto a regra de corte europeia retém uma parcela considerável dos impactos em todas as categorias, os subsistemas excluídos pelo LEED afetam principalmente categorias não avaliadas, mas em que a produção de materiais de construção tem efeito relevante, como ecotoxicidades, toxicidade humana e depleção abiótica. Adicionalmente, a livre escolha de três categorias ambientais propicia redundância de informação, caso elas façam parte de um mesmo cluster. Para equilibrar a viabilidade da ACVed, enquanto se assegura a integridade das conclusões, recomendamos que a certificação adicione subsistemas na avaliação até que mais de $75 \%$ dos metais sejam computados, e amplie estrategicamente o conjunto de categorias avaliadas mandatoriamente. Estudos adicionais são agora necessários para confirmar estas proposições.
\end{abstract}

Palavras-chave: Avaliação do Ciclo de Vida. ACV de edificação completa. Regras de corte. LEED. Certificação.

\begin{abstract}
The scarce publications on whole-building lifecycle assessment (wbLCA) highlights the need to reduce the number of flows considered. Cutoff rules facilitate inventory modeling, but their effects are underexplored in the literature. This work investigates how the most well-known cutoff approaches used in wbLCA - by mass and energy, as indicated by the EN 15804 standard, and by building elements, as adopted by LEED v4 certification - influence the assessment results, relatively to a baseline, complete inventory. Cradle to grave impacts was calculated for two case studies. SimaPro v8.5/9.0 supported processes composition and adaptation from the Ecoinvent database. CML-IA baseline and CED methods were used for impact assessment, and k-means clustering highlighted relationships amongst environmental categories. Whilst the European cutoff rule retains a considerable share of impacts on all categories, the elements excluded by the LEED approach mostly impact non-assessed categories, such as ecotoxicity, human toxicity, and abiotic depletion. These categories are highly affected by some building materials production. The free choice of three environmental categories to assess may also result in information redundancy whenever they pertain to the same cluster. To balance inventory completion viability while ensuring the integrity of wbLCA conclusions, we recommend that the certification compute over $75 \%$ of the metals used in the building and strategically expand the set of categories evaluated on a mandatory basis. Additional studies are now needed to confirm our findings and validate propositions for certificationoriented wbLCA.
\end{abstract}

Keywords: Life Cycle Assessment. Whole-building LCA. Cutoff rules. LEED. Certification.

How to cite this article:

PULGROSSI, Lizzie Monique; GOMES, SILVA Gomes da. Influência de regras de corte de inventário nos resultados de ACV de edificações. PARC Pesquisa em Arquitetura e Construção, Campinas, SP, v. 11, p. e020026, 2020. DOI: http://dx.doi.org/10.20396/parc.v11i0.8658259 


\section{Introdução}

A avaliação de ciclo de vida (ACV) apresenta uma avaliação quantitativa dos impactos ambientais causados pelos processos produtivos a partir do seu consumo de massa e energia, contemplando todo o ciclo de vida do produto (desde a extração de matériaprima, passando pela fabricação e uso, até o seu descarte final), o que permite traçar seu perfil ambiental e identificar oportunidades de melhoria (TODD, 2012).

Ao tratar uma edificação completa, composta por inúmeros elementos e processos construtivos, o emprego da ACV torna-se uma tarefa complexa, que demanda tempo, experiência do avaliador e o inventário de um grande conjunto de dados, por vezes indisponíveis ou inexistentes. Soma-se a isso a extensa vida útil da edificação, que induz a diversas suposições e a adoções de dados genéricos, principalmente referentes às etapas de uso e manutenção e de fim de vida.

A revisão da literatura aponta diferentes estratégias de simplificação da avaliação, como a exclusão de etapas menos relevantes no ciclo de vida; o foco em determinadas categorias de impacto que influenciam decisões estratégicas; ou a predefinição de cenários e o uso de calculadoras de inventário como limitadoras das escolhas do usuário (SOUST-VERDAGUER; LLATAS; GARCÍA-MARTÍNEZ, 2016).

As chamadas 'regras de corte' adicionam uma camada extra de simplificação à construção do inventário, ao excluir fluxos com base em critérios predefinidos, e podem representar um auxílio valioso na viabilização da modelagem, disseminando o uso da técnica de ACV em edificações inteiras (ACVed). Variações substanciais na sua aplicação, no entanto, influenciam os resultados da avaliação e podem, eventualmente, comprometer a tomada de decisões, mas é um enfoque inexplorado na literatura. De fato, a revisão sistemática em periódicos realizada previamente (PULGROSSI, 2020) não registrou qualquer trabalho nessa linha específica.

$\mathrm{Na}$ literatura e na prática de ACV há basicamente duas condutas para corte de inventário: por contribuição em massa e energia, encontrados nas normas e recomendações internacionais sobre ACVed (CEN, 2012; EEBGUIDE, 2012), ou por subsistema construtivo, adotada por certificações ambientais, como o Leadership for Environmental and Energy Design - LEED v4 (USGBC, 2013). Os critérios de corte previstos nas normas permitem excluir contribuições até $5 \%$ da massa e energia totais, enquanto a avaliação abrange categorias nos oito grupos ambientais principais. Embora o LEED v4 tente equilibrar simplificação e significância de resultados, sua abordagem obviamente implica em uma regra de corte muito maior e limita o escopo a algumas categorias ambientais. Esta reflexão levanta uma série de questões de pesquisa, dentre elas, as que procuramos responder com este trabalho:

- Qual o significado de se reduzir o escopo da avaliação para englobar apenas (1) estrutura e envelope e (2) três - dentre seis - categorias de impacto, como o LEED v4 propõe?

- Qual e quanto impacto que está sendo negligenciado? Qual a relevância desta parcela?

- Existe evidência de um ponto de equilíbrio entre um corte mais substancial, que facilite a realização de ACVed, mas não comprometa suas principais conclusões?

Para verificar a hipótese de que impactos consideráveis são negligenciados na perspectiva do LEED v4, prejudicando a compreensão adequada dos resultados da avaliação, o objetivo deste trabalho é investigar a influência da aplicação das duas principais abordagens de exclusão de fluxos do inventário utilizadas em ACVed - por 
massa e energia, indicada pela norma EN 15804:2012 (CEN, 2012), e por subsistema construtivo, nos moldes adotados pelo LEED v4.

\section{Práticas de exclusão de fluxos de inventário em ACV de edificações (regras de corte)}

O emprego geral de regras de corte em ACV é norteado pela ISO 14044:2006 (ISO, 2006b) e pelo ILCD Handbook (EC JRC-IES, 2010), que orientam a exclusão de fluxos com base em análise de contribuição (em massa, em energia) e significância ambiental do item analisado. A norma ISO 14044:2006 (ISO, 2006b) ressalta que o uso de regras de corte deve ser restrito a inventários completos, para limitar os efeitos de simplificações cumulativas. O ILCD Handbook (EC JRC-IES, 2010) recomenda a máxima inclusão possível, por razões de transparência e comunicação, mas admite excluir fluxos insignificantes, que representem menos de $10 \%$ da parcela do impacto não computada. Para uma completeza de $95 \%$, por exemplo, seriam insignificantes os fluxos inferiores a $0,5 \%$ do impacto em tela. Esta regra reduz os fluxos de inventários em cerca de 50 a $80 \%$, facilitando o controle de qualidade e a interpretação (GOMES et al., 2018b).

A grande referência para aplicação de ACVed é a norma EN 15978:2011 (CEN, 2011). Utilizada como guia mesmo em países não europeus, esta norma adapta os passos da ACV à aplicação especifica para edificações, e estabelece, entre outros, definições, escopos, e a estrutura modular para informação, composta pelos estágios do ciclo de vida a considerar, desde a produção de materiais, componentes e sistemas, a construção, o uso e manutenção, até a etapa de fim de vida. Cada etapa é subdividida em módulos (A1-3; A4-5; B1-7; C1-4 e D), com a opção de computar no chamado 'Módulo D' aqueles benefícios potencialmente concretizáveis depois de finalizado o ciclo de vida sob análise (Figura 1).

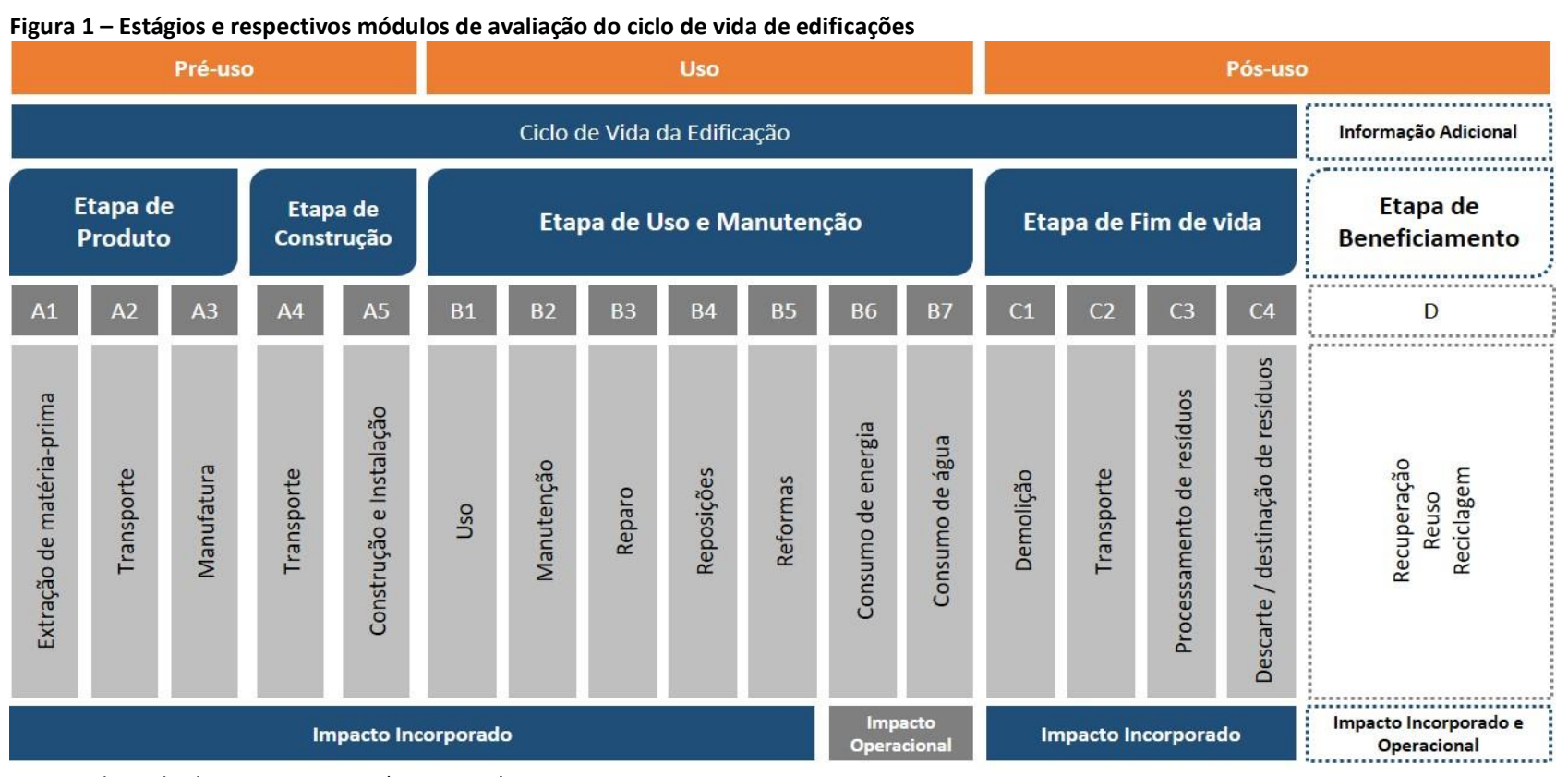

Fonte: adaptado de EN 15978:2011 (CEN, 2011).

Quanto a regras de corte, a norma EN 15978:2011 referencia uma outra, a EN 15804:2012 (CEN, 2012), desenvolvida para nortear declarações ambientais de produtos de construção. Esta norma alinha-se à ISO 14044 (ISO, 2006b), ao declarar que devem ser incluídas todas as entradas e saídas para um processo para o qual haja dados disponíveis, e acrescenta que eventuais lacunas podem ser preenchidas com dados 
médios ou genéricos, baseadas em hipóteses conservadoras. Na ausência incontornável de dados apropriados, a norma europeia admite a aplicação de cortes no inventário. Os dois últimos casos - uso de dados médios/genéricos e de regras de corte - devem ser documentados de forma transparente, especialmente no caso de estudos comparativos.

Havendo corte de inventário, a EN 15804:2012 (CEN, 2012) segue uma abordagem simplificada e admite a omissão de fluxos de entrada e de saída em processos unitários que representem menos de $1 \%$ da massa e da energia total, desde que, em cada módulo (A1-A3; A4-A5; B1-B5; B6-B7;C1-C4; D) do ciclo de vida, a soma excluída seja inferior a 5\% da massa e da energia total (CEN, 2012). Esta decisão corresponde a uma completeza de $90 \%$ na contabilização destas categorias, segundo o critério do ILCD Handbook (EC JRC-IES, 2010). Novamente, prevalece o conservadorismo e bom senso para incluir, como precaução, elementos com significância ambiental, ainda que passíveis de exclusão segundo a regra de corte aplicada.

O projeto EeBGuide (2012) trouxe orientações adicionais para a implementação prática das normas EN 15804/15978, e indica que, se as disposições do ILCD Handbook não forem alcançáveis, então as regras de corte apresentadas nestas normas podem ser usadas. Nesta interpretação, materiais - e não apenas processos unitários - podem ser omitidos nas proporções indicadas de $1 \%$ (individualmente) e $5 \%$ do total. O tipo de estudo já não configuraria uma 'ACVed completa', mas ACVed simplificada ou para triagem (screening). Nestes casos, as exclusões deveriam ser justificadas pelo avaliador, à luz de uma lista de produtos de construção e equipamentos técnicos a serem obrigatoriamente incluídos nas avaliações. Sempre que disponíveis, valores-default para a Europa poderiam ser utilizados, ainda que não representativos de um produto específico, para limitar as exclusões do inventário (etapa de validação), e equilibrar a exigência de completeza com a praticidade de realização dos estudos.

A segunda corrente de corte de inventário praticada em ACVed pauta-se pela exclusão de componentes por subsistema construtivo, frequentemente observada na literatura (SOUST-VERDAGUER; LLATAS; GARCÍA-MARTÍNEZ, 2016) e adotada por certificações ambientais como BREEAM, LEED, DGNB, Green Globes e Green Star (ISMAEEL, 2018). A certificação LEED, por exemplo, incluiu o uso da ACVed para avaliação de materiais e recursos a partir de sua versão 4 , porém considerando apenas elementos da estrutura e envelope (USGBC, 2013). Apesar de em linha com sua modalidade de certificação mais comum - core \& shell - e com a literatura, que consistentemente reconhece estrutura e envelope como os principais contribuintes para as cargas ambientais de uma edificação (DOBBELSTEEN; ARETS; NUNES, 2007; HAAPIO; VIITANIEMI, 2008; KELLENBERGER; ALTHAUS, 2009; MOON, 2009), fica evidente que esta restrição configura uma regra de corte muito mais ousada que a exclusão com base em análise de contribuição, recomendada em diretrizes e normas de ACVed.

\section{Método}

\section{Estudos de caso}

Como variações - construtiva, estrutural e de massa - refletem-se na parcela excluída pelas regras de corte, a seleção dos casos estudados (Quadro 1) foi norteada pela hipótese de que a aplicação dos critérios de exclusão a edificações com diferentes características de materialidade e contribuições de subsistemas poderia não só evidenciar a sua influência, como revelar eventuais padrões nos resultados das ACVed. 
PULGROSSI, Lizzie Monique; SILVA, Vanessa Gomes da

Influência de regras de corte de inventário nos resultados de ACV de edificações

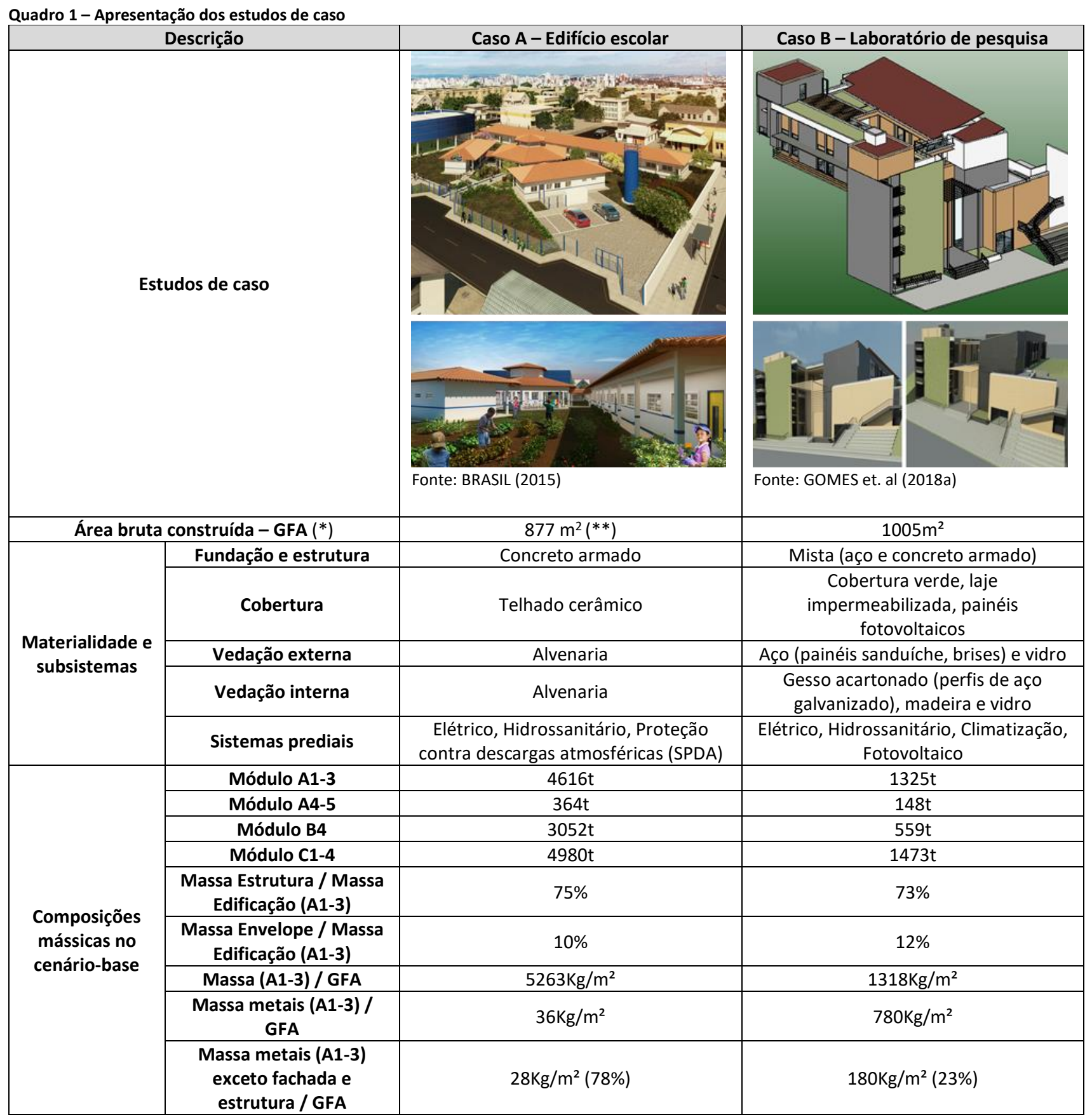

Nota: Informações adicionais de inventário encontram-se no Apêndice A. ( $\left.{ }^{*}\right)$ Gross Floor Area (GFA). ( ${ }^{* *}$ ) Extraído do arquivo DWG fornecido pela FNDE (BRASIL, 2015). Fonte: as autoras.

Assim, o estudo A corresponde ao "Espaço Educativo Rural e Urbano de seis salas de aula", um modelo de edificação escolar replicável nacionalmente, desenvolvido pelo Fundo Nacional de Desenvolvimento da Educação - FNDE (BRASIL, 2015), para atender até 360 alunos em dois turnos ou 180 alunos em período integral. A edificação desenvolve-se em um pavimento térreo formado por três blocos retangulares dispostos ao redor de um pátio circular central contendo o refeitório, e representa o padrão construtivo típico de construções públicas convencionais brasileiras: simples, com estrutura de concreto armado, vedações em alvenaria e cobertura em telhas cerâmicas. A documentação do projeto-padrão (memorial descritivo, projetos, nota técnica) está disponível para download a partir do site do FNDE. 
Já o estudo $B$ refere-se a um laboratório de pesquisa com três pavimentos, projetado para atender aos requisitos de desempenho ambiental e energético das certificações LEED BD+C 2009 e PROCEL Edificações, e detalhado em GOMES et al. (2018a). Este edifício compreende estrutura mista, com pilares e vigas de aço, e uso mínimo de concreto em lajes e fundações. As vedações externas são em painéis sanduíche compostos por chapas de aço pintado e isolamento de poliuretano, com brises de chapas de aço protegendo as aberturas voltadas para norte. As divisórias internas são de gesso acartonado ou de madeira com vidro. A cobertura mescla telhado verde, diferentes tecnologias de painéis fotovoltaicos e uma pequena laje impermeabilizada.

Apesar das áreas construídas serem aproximadas, o Caso B é uma edificação muito mais leve, com menos de $1 / 3$ da massa do Caso A. Essa proporção se mantém ao longo do ciclo de vida, exceto pela entrada de novos materiais na etapa de uso e manutenção, que é muito menor no segundo caso. Em ambos os casos, a estrutura e o envelope constituem mais de $80 \%$ da massa inicial da edificação, com absoluta predominância do sistema estrutural. A síntese dos inventários de ciclo de vida (ICV) dos dois casos analisados é apresentada no Apêndice $A$.

Hipóteses e justificativas de modelagem

As modelagens seguiram as normas internacionais ISO 14040:2006 (ISO, 2006a) e ISO 14044:2006 (ISO, 2006b), as normas europeias EN 15978:2011 (CEN, 2011) e EN 15804:2012 (CEN, 2012), além das recomendações do EeBGuide Project (2012), também de âmbito europeu. A plataforma SimaPro v8.5/9.0 apoiou a composição e adaptação dos processos "rest of the world" (RoW) extraídos da base de dados secundários Ecoinvent v3.4/3.5 para a matriz elétrica e fontes da água compatíveis com o contexto brasileiro (Quadro 2).

A avaliação pelo LEED v4 considera 60 anos de vida útil para a edificação. A EN 15978:2011 (CEN, 2011) não determina a vida útil a ser considerada, mas o EeBGuide (2012) recomenda a adoção de um período de referência de 50 anos, também apontado pelo IEA EBC Annex 57 (IEA, 2016) como o mais frequentemente utilizado na literatura. Para compatibilizar os dois métodos, a vida útil de referência das edificações foi padronizada em 50 anos, segundo as normas norteadoras de ACVed, e o corte foi aplicado à etapa de produto (módulos A1-A3), como determinado pelo LEED v4. Os impactos nestes dois cenários foram, então, estimados do berço ao túmulo e contrastados com aqueles obtidos para um cenário-base, que representa a maior completeza de inventário.

Uma ACVed segundo o LEED v4 deve considerar a categoria de mudança climática e eleger outras duas dentre depleção da camada de ozônio estratosférico; formação de ozônio troposférico, acidificação, eutrofização, e depleção de recursos energéticos não renováveis (USGBC, 2013). Todas estas são categorias de impacto em ponto médio ou midpoint (LESSARD et al., 2017), assim como as categorias previstas nas normas EN 15978:2011 (CEN, 2011) e EN 15804:2012 (CEN, 2012), o que justifica o emprego desta abordagem de avaliação de impactos no ciclo de vida (AICV) no estudo.

Nem as normas europeias, nem o LEED especificam um método AICV em particular, apenas as categorias a serem contempladas. Assim, optamos por combinar os métodos CML-IA baseline e demanda cumulativa de energia (Cumulative energy demand - CED). Dentre os métodos AICV em ponto médio, o CML-IA conta com o maior número de fatores de caracterização disponíveis (ACERO; RODRIGUEZ; CIROTH, 2015), além de ser o mais utilizado na literatura (SAADE; SILVA; GOMES, 2014) e pelas principais plataformas de ACV na derivação de fatores de caracterização faltantes para outros 
métodos AICV, como o Impact2002 (ACERO; RODRIGUEZ; CIROTH, 2015), e os métodos EPD e EN 15804 + A2 (PRÉ, 2020).

A versão baseline do CML-IA contempla os oito grupos de categorias de impacto mais comumente utilizados em ACV, que compreendem as seis categorias avaliadas pelo LEED v4, além de ecotoxicidade (terrestre, de água doce e marinha), toxicidade humana e depleção de recursos abióticos. Adicionamos o método CED para avaliar a significância ambiental dos fluxos em termos de sua contribuição para a energia total, passo necessário para efetuar os cortes de inventário segundo a EN 15804:2012 (CEN, 2012). Assim, a etapa de AICV abrangeu, ao todo, 13 categorias de impacto em ponto médio (midpoint), que ofereceram excelente ajuste às necessidades deste estudo.

Quadro 2 - Aspectos metodológicos utilizados para modelagem ACVed

\begin{tabular}{|c|c|}
\hline Descrição & Características \\
\hline Objetivo & Calcular os impactos ambientais do ciclo de vida da edificação completa \\
\hline Unidade Funcional & Toda a edificação avaliada \\
\hline Escopo / Fronteira do sistema & Berço ao túmulo / Etapas A1-3; A4-5; B4; C1-4 \\
\hline Limite Geográfico & Campinas, Brasil \\
\hline Período de referência & 50 anos \\
\hline Base de dados de inventário & $\begin{array}{l}\text { Ecoinvent v3.4 e v3.5 - adaptação de processos com "allocation, cut-off by classification - unit", para } \\
\text { contexto brasileiro (matriz elétrica, origem da água e processos "RoW") }\end{array}$ \\
\hline Software ACV & SimaPro $8.5 / 9.0$ \\
\hline Metodologia de avaliação & CML-IA baseline v3.05 e CED v1.11 \\
\hline $\begin{array}{l}\text { Categorias de avaliação de } \\
\text { impacto }\end{array}$ & $\begin{array}{l}\text { CML-IA baseline: Aquecimento global (GWP, em kg CO2eq); Depleção abiótica - combustíveis } \\
\text { fósseis (ADPff, em MJ); Depleção da camada de ozônio (ODP, em kg CFC-11 eq); Formação do ozônio } \\
\text { fotoquímico (PCOP, em kg C2H4 eq); Acidificação (AP, em kg SO2eq); Eutrofização (EP, em kg } \\
\text { PO4eq); Ecotoxicidade em água doce (FAETP, em 1,4-DBeq); Ecotoxicidade em água marinha } \\
\text { (MAETP, em 1,4-DBeq); Ecotoxicidade terrestre (TAETP, em 1,4-DBeq); Toxicidade Humana (HTP, em } \\
\text { 1,4-DBeq); Depleção abiótica - recursos (ADPres, em kg Sbeq). } \\
\text { CED: Energia Primária Não-Renovável (MJ); Energia Primária Renovável (MJ). }\end{array}$ \\
\hline Subsistemas construtivos & $\begin{array}{l}\text { ESTRUTURA E ENVELOPE: Fundação e superestrutura, Cobertura, Vedações externas, Janelas e } \\
\text { portas externas, Acabamentos externos, } \\
\text { SUBSISTEMAS INTERNOS: Vedações internas, Acabamentos internos, Portas internas, Instalação } \\
\text { hidrossanitária, Instalação elétrica e dados, Instalações adicionais (climatização, fotovoltaico, } \\
\text { proteção contra descargas atmosféricas etc.). } \\
\text { Obs.: Vedações, Acabamentos e Portas e janelas foram separados para facilitar a observação da } \\
\text { contribuição dos materiais constituintes. }\end{array}$ \\
\hline
\end{tabular}

\section{Etapas do ciclo de vida consideradas}

$\mathrm{Na}$ etapa de produto ( $\mathrm{A} 1-\mathrm{A} 3)$ do inventário da $\mathrm{ACV}$ ed, os componentes e quantitativos foram distribuídos em 11 subsistemas construtivos, definidos com base na Tabela de Composições de Preços para Orçamentos - TCPO (PINI, 2008). Não foram considerados serviços preliminares, temporários e componentes não aderidos ao edifício, como: movimentação de terra, abrigos, instalações temporárias, mobiliário etc. Os consumos de combustíveis dos equipamentos de construção (A5) e demolição (C1) foram quantificados mediante consulta ao mercado, por unidade de área construída. As perdas de materiais durante a etapa de construção (A5) observaram os valores médios do TCPO, quando disponíveis, ou de 10\% para os itens não indicados.

A tabela C6 da norma de desempenho NBR 15575:2013 (ABNT, 2013) balizou a definição do fator de reposição (a 100\% de substituição) considerado para os diferentes subsistemas (etapa B4), ao longo dos 50 anos da vida útil de referência adotada para a edificação. Como o escopo de ACV da certificação LEED v4 contempla apenas os impactos incorporados nos materiais construtivos, numa perspectiva do berço ao túmulo, os módulos operacionais B6 (energia) e B7 (água), e o módulo D foram desconsiderados. 
A modelagem de fim de vida considerou $100 \%$ dos resíduos de construção e demolição (RCD) destinados para aterro sanitário de materiais inertes ( $\left.\mathrm{C}_{1}-\mathrm{C}_{2}-\mathrm{C}_{4}\right)$, como adotado por Morales et al. (2019). Analogamente aos demais módulos que envolvem impactos de transporte, as distâncias e combustíveis considerados na modelagem do fim de vida representam a situação atual da cidade de Campinas - SP.

\section{Cenários de estudo}

Foram estabelecidos três cenários de inventário: um cenário-base, abrangendo a modelagem completa da edificação, mais um cenário orientado por cada regra de corte analisada. As análises foram, então, embasadas pelo contraste dos resultados das diferentes categorias de impacto para os cenários considerados.

No cenário 2, adotou-se a abordagem estabelecida pela certificação LEED v4. Já o cenário 1 observou a regra de corte apresentada pela norma europeia EN 15804. Para compatibilidade com a regra utilizada no LEED v4, os materiais foram distribuídos nos respectivos subsistemas da edificação e o corte aplicado apenas sobre fluxos na etapa de produto (A1-3). Uma vez aplicado o corte, os impactos dos materiais retidos foram considerados para avaliação do berço ao túmulo.

A prospecção de eventuais padrões e regras de associação entre categorias de impacto foi apoiada por análise de agrupamento por similaridade utilizando k-means, um algoritmo de aprendizagem não supervisionado. Numa aglomeração não hierárquica, a medida de distância representa a similaridade: arbitra-se um número de agrupamentos (K); assume-se centros (centroides) para os agrupamentos; calcula-se a distância de cada observação até os centros; e agrupa-se os objetos com distância do centro inferior a um valor pré-estabelecido (distância Euclidiana mínima). O algoritmo então repete esse processo até a convergência, quando os clusters tornam-se estáveis, e sua composição não mais se altera. O objetivo é obter a maior homogeneidade possível dentro de um cluster e a maior heterogeneidade entre clusters. Em termos matemáticos, o que se busca na clusterização é uma quantidade de agrupamentos em que a soma dos quadrados intra-clusters (wcss, da expressão em inglês "within-clusters sum-of-squares") seja a menor possível, idealmente igual a zero. A aglomeração por $k$ means pode ser feita de diversas formas, como por códigos em Matlab, Visual Basic ou Python. O código utilizado neste trabalho compreende pacotes Python (pandas, NumPy, scikit-learn, Seaborn e Matplotlib).

\section{Resultados}

\section{Estudo A - Edifício escolar}

O inventário completo deste estudo apresentou 40 processos de materiais. A regra de corte do cenário 1 reteve 15 processos ( $95 \%$ de massa e $97 \%$ da energia obtidas na modelagem completa). O cenário 2 coincidentemente reteve 15 processos, mas que corresponderam a $85 \%$ da massa e da energia obtidas na modelagem completa. Nos três cenários (Figura 2), os subsistemas Fundação e superestrutura e Cobertura se sobressaem, uma vez que o concreto e o madeiramento do telhado, respectivamente representam cerca de $75 \%$ da massa (3430t, no cenário-base) e da energia (20TJ, no cenário-base) da edificação. 


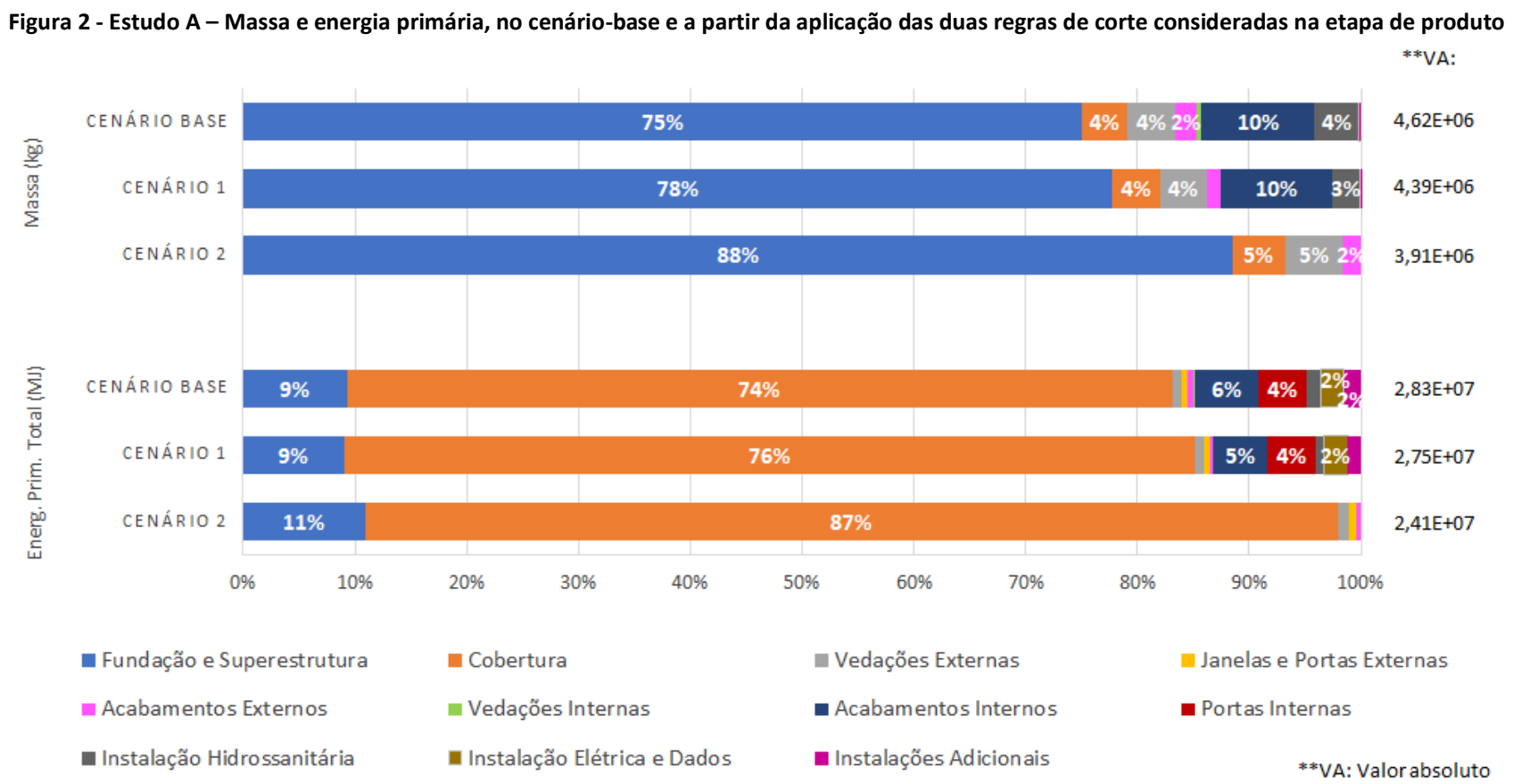

No cenário 1, entre $68 \%$ e $89 \%$ dos impactos são computados a partir dos processos retidos pela regra de corte aplicada. $O$ agrupamento $k$-means segundo dois clusters (Figura 3) evidencia a semelhança entre aquecimento global, depleção abiótica (combustíveis fósseis), depleção da camada de ozônio, formação de ozônio fotoquímico, acidificação, ecotoxicidade terrestre e depleção de recursos abióticos ( $\mathrm{K}_{\mathrm{EN}}$, com retenção de impactos de cerca de $85,9 \%$ ) e entre eutrofização, ecotoxicidade de água doce e marinha, e toxicidade humana ( $\mathrm{K}_{\mathrm{EN}_{2}}$, com retenção de impactos em torno de $72,8 \%$ ). A variação na retenção de impacto entre os dois grupos é inferior a $13 \%$.

Já no cenário 2 (LEED v4), o agrupamento k-means segundo três clusters (Figura 3) revela um primeiro grupo - formado pelas categorias aquecimento global, depleção abiótica (combustíveis fósseis) e depleção da camada de ozônio - em que pouco mais da metade $\left(\mathrm{K}_{1}-52,3 \%\right)$ dos impactos referem-se a estrutura e envelope, devido ao concreto e à argamassa cimentícia. Esta seria a parcela retida para a avaliação pelo LEED v4. Para o segundo grupo ( $\mathrm{K}_{2}-38 \%$ ) - formado pelas categorias formação de ozônio fotoquímico e acidificação - estrutura e envelope correspondem a pouco mais de 1/3 dos impactos. Finalmente, o terceiro grupo $\left(\mathrm{K}_{3}-22,3 \%\right)$ - composto por eutrofização, ecotoxicidades, toxicidade humana e depleção de recursos abióticos - é o pior representado na regra de corte por estrutura e envelope: apenas 18 a 26\% dos impactos seriam retidos, caso todas estas categorias fossem avaliadas para fins da certificação; mas apenas eutrofização está entre as seis categorias-alvo do LEED v4.

Com pouco mais de $8 \%$ da massa no ciclo de vida, os sistemas prediais (instalações elétricas e dados, hidrossanitárias, e adicionais) imprimiram de 56 a 71\% dos impactos nas categorias de ecotoxicidades aquática e terrestre e toxicidade humana (Figura 4), devido ao uso de metais (cobre e aço carbono) em cabos elétricos e tubulações (Figura 5). Os acabamentos internos, principalmente revestimentos cerâmicos, responderam por quase $1 / 3$ dos impactos em depleção abiótica de recursos. 
PULGROSSI, Lizzie Monique; SILVA, Vanessa Gomes da

Influência de regras de corte de inventário nos resultados de ACV de edificações

Figura 3 - Estudo A - Impactos retidos segundo cada regra de corte, relativamente ao cenário-base. 0 valor absoluto (VA) no topo de cada coluna representa $100 \%$ dos impactos computados. Em vermelho, as categorias consideradas pelo LEED v4. A contribuição para a massa no ciclo de vida é indicada para referência. $\mathrm{K}_{\mathrm{EN} 1}$ e $\mathrm{K}_{\mathrm{EN} 2}$ (cenário 1) e $\mathrm{K}_{1}, \mathrm{~K}_{2}$ e $\mathrm{K}_{3}$ (cenário 2) são os centroides dos clusters obtidos por agrupamento $k$-means.

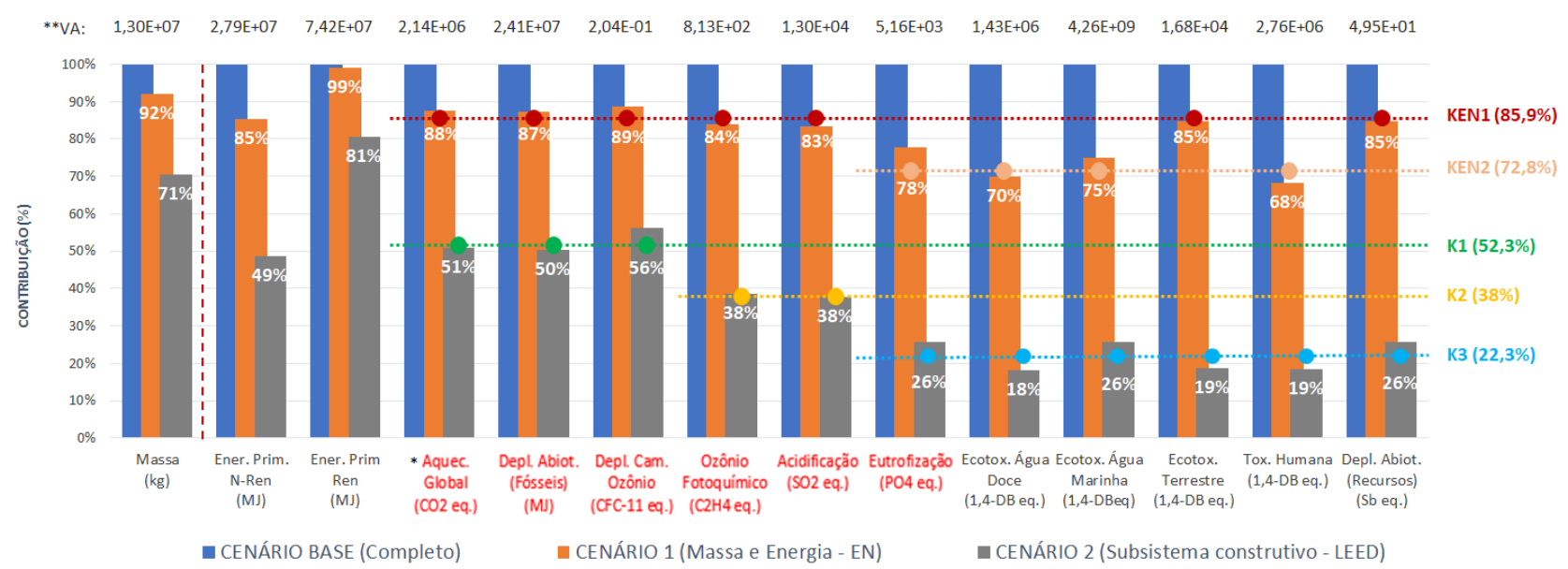

Fonte: as autoras.

Figura 4 - Estudo A - Impactos (valor absoluto (VA) e contribuições) por subsistema da edificação, para o cenário-base. Em vermelho, as categorias consideradas pelo LEED v4. A linha tracejada destaca a contribuição dos elementos de estrutura e envelope. A contribuição para a massa no ciclo de vida é indicada para referência.

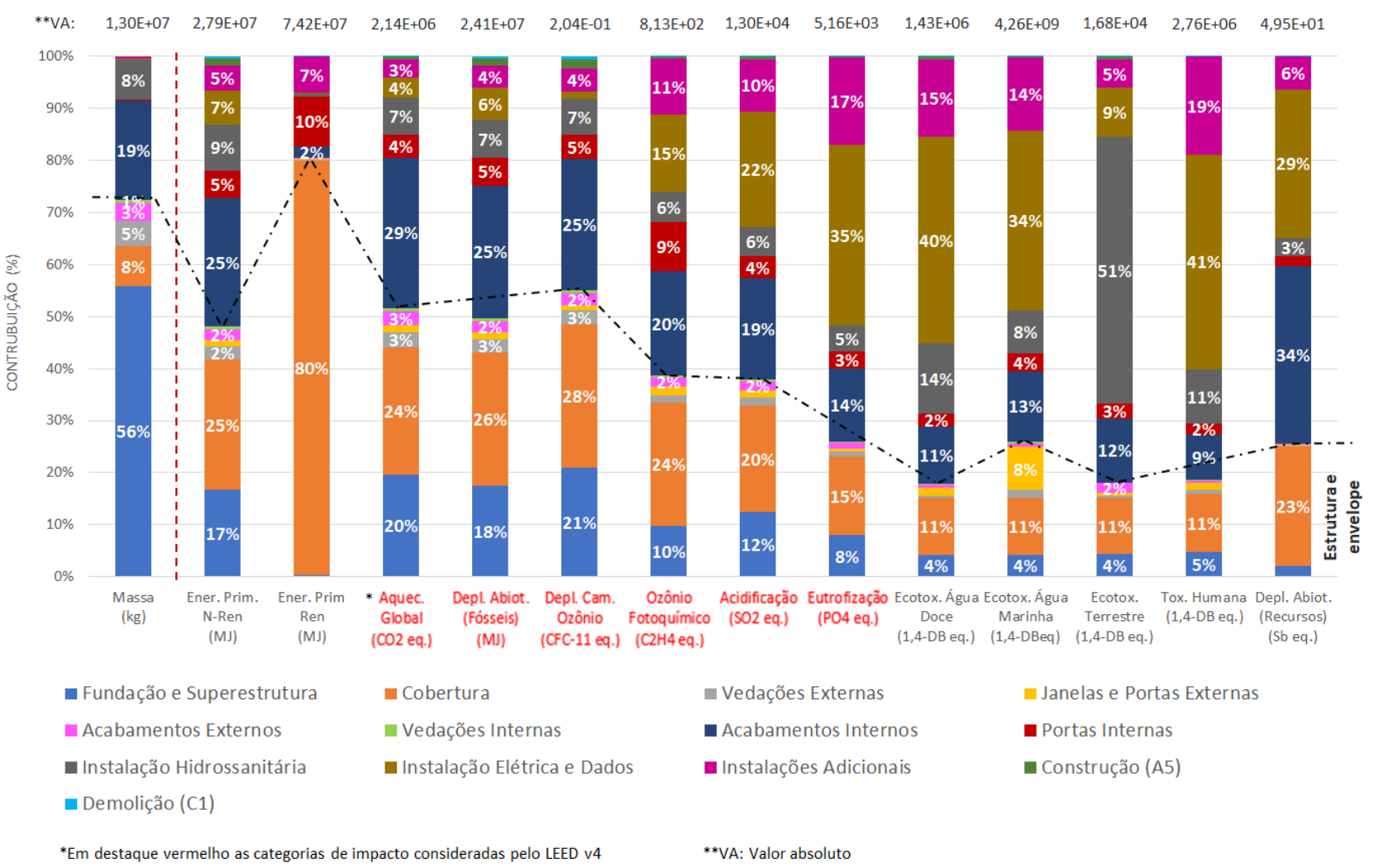

Fonte: as autoras. 
Figura 5 - Estudo A - Impactos (valor absoluto (VA) e contribuições) por material, para o cenário-base. Em vermelho, as categorias consideradas pelo LEED v4. A contribuição para a massa no ciclo de vida é indicada para referência.

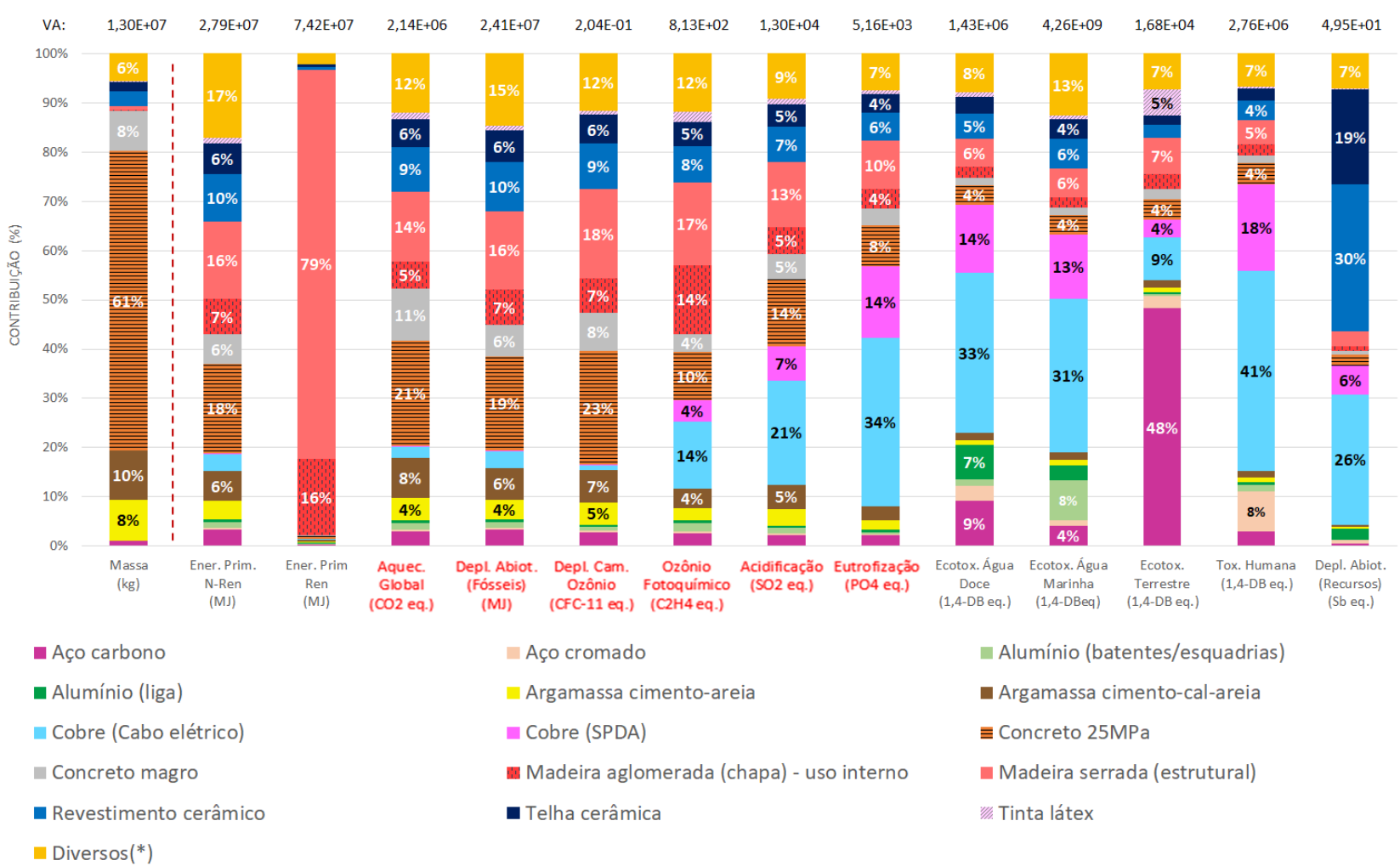

(*) Itens com valores inferiores a 5\% em todas as categorias de impacto: Aço (vergalhões); Aço galvanizado; Alumínio (chapa); Alumínio (lingote); Argamassa colante; Bloco concreto; Bloco/Tijolo cerâmico; Borracha (EPDM); Brita; Bronze; Cerâmica sanitária; Ferro fundido; Ferro galvanizado; Latão; Madeira (batentes/esquadrias); Massa corrida/cola (PVA); Nylon; Pedra natural polida; Plástico ABS; Polietileno (PEAD); Polipropileno (PP); Cloreto de polivinila (PVC); Tinta betuminosa; Tinta epóxi; Tinta esmalte; Vidro comum; Construção (A5); Demolição (C1).

Fonte: as autoras.

\section{Estudo B - Laboratório de Pesquisa}

O inventário inicial deste estudo de caso contemplou 21 processos de materiais. Após a aplicação das regras de corte, foram retidos 11 processos, no cenário 1, e 8 processos, no cenário 2, com perfis parecidos de contribuições na etapa de produto (Figura 6). Em todos os cenários, o subsistema Fundação e superestrutura concentrou massa e energia devido aos vergalhões de aço (562t e 13,5TJ, no cenário-base). Na massa, o destaque de contribuições seguiu para as vedações internas em gesso acartonado e perfis de aço galvanizado, e vedações e acabamentos externos. Mas na energia primária, as vedações internas cederam lugar à participação ampliada das vedações externas em painéis sanduíche de aço, das janelas e portas externas, e das instalações prediais adicionais (climatização).

No cenário 1, o agrupamento k-means evidencia os mesmos clusters observados no Estudo A (Figura 7), exceto pela migração da categoria de acidificação para o grupo com eutrofização, ecotoxicidade de águas doce e marinha, e toxicidade humana. Os processos retidos pela regra de corte aplicada correspondem a uma parcela maior dos

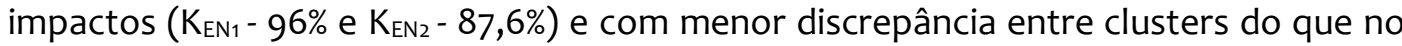
Estudo A.

O cenário 2 (LEED v4) segue agrupamento parecido com o do cenário 1 (Figura 7), com parcelas de retenção de impactos sempre maiores que aquelas observadas para o Estudo A. O primeiro cluster ( $\left.K_{1}-79 \%\right)$, que abrange aquecimento global, depleção abiótica (combustíveis fósseis), depleção da camada de ozônio, formação de ozônio 
fotoquímico, ecotoxicidade de água doce, e toxicidade humana, apresenta a maior parcela de impactos retida para a avaliação pelo LEED v4, principalmente devido ao aço nos painéis de vedação e na estrutura metálica. O segundo grupo $\left(K_{2}-65 \%\right)$ é formado pelas categorias acidificação, eutrofização e ecotoxicidade de água marinha. Finalmente, o terceiro grupo $\left(\mathrm{K}_{3}-39,5 \%\right)$, composto por ecotoxicidade terrestre e depleção abiótica (recursos), é o pior representado na abordagem do LEED v4: pela regra de corte, apenas cerca de $40 \%$ dos impactos seriam retidos com a estrutura e o envelope, mas nenhuma destas categorias é avaliada para fins da certificação. A baixa retenção de impactos na categoria de depleção de recursos abióticos chama particularmente a atenção.

Figura 6 - Estudo B - Massa e energia primária, no cenário-base e a partir da aplicação das duas regras de corte consideradas na etapa de produto

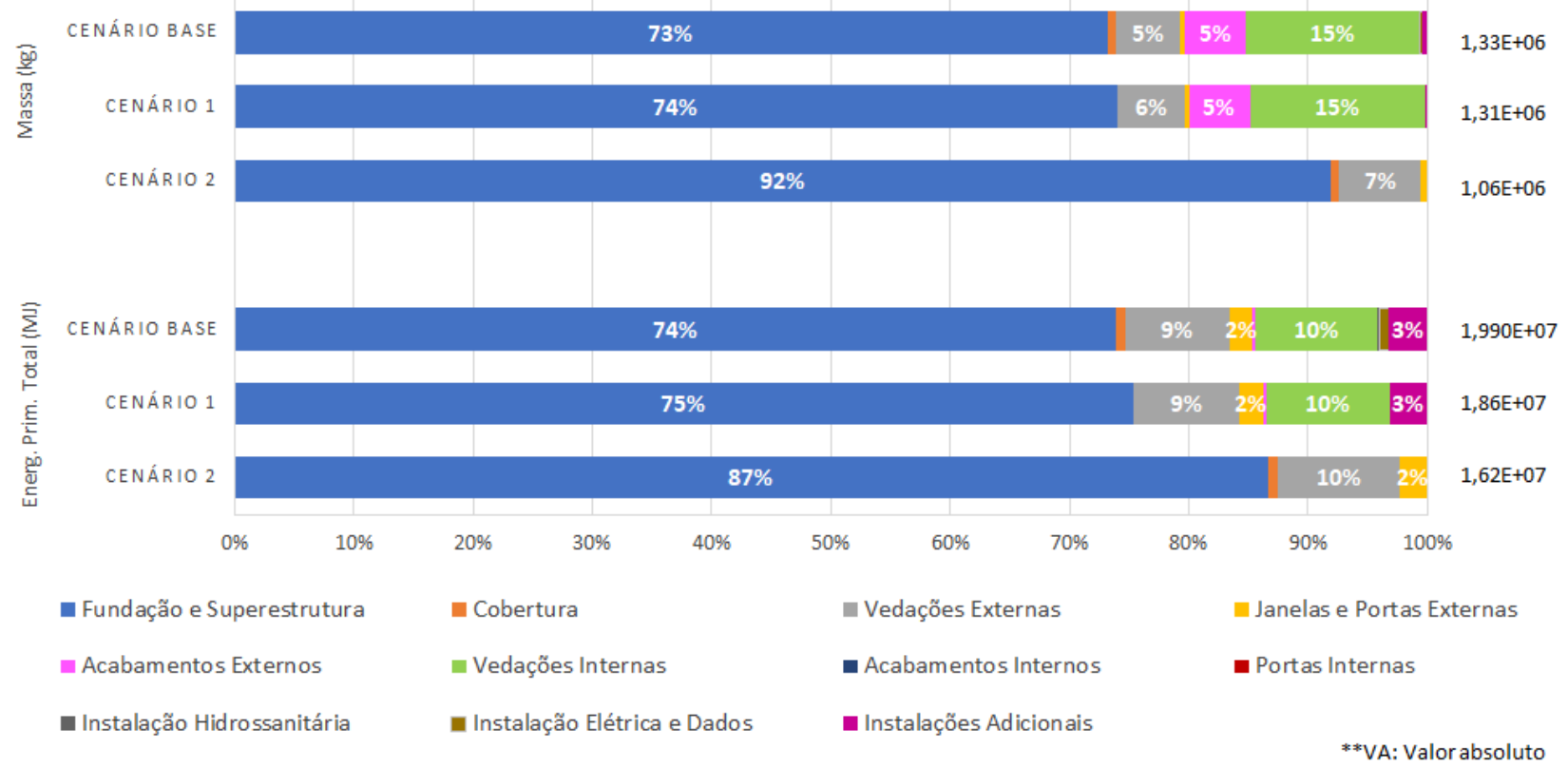

Fonte: as autoras.

Figura 7 - Estudo B - Impactos retidos segundo cada regra de corte, relativamente ao cenário-base. O valor absoluto (VA) no topo de cada coluna representa $100 \%$ dos impactos computados. Em vermelho, as categorias consideradas pelo LEED v4. A contribuição para a massa no ciclo de vida é indicada para referência. $K_{E N 1}$ e $K_{E N 2}$ (cenário 1) e $K_{1}, K_{2}$ e $K_{3}$ (cenário 2) são os centroides dos clusters obtidos por agrupamento $k$-means.

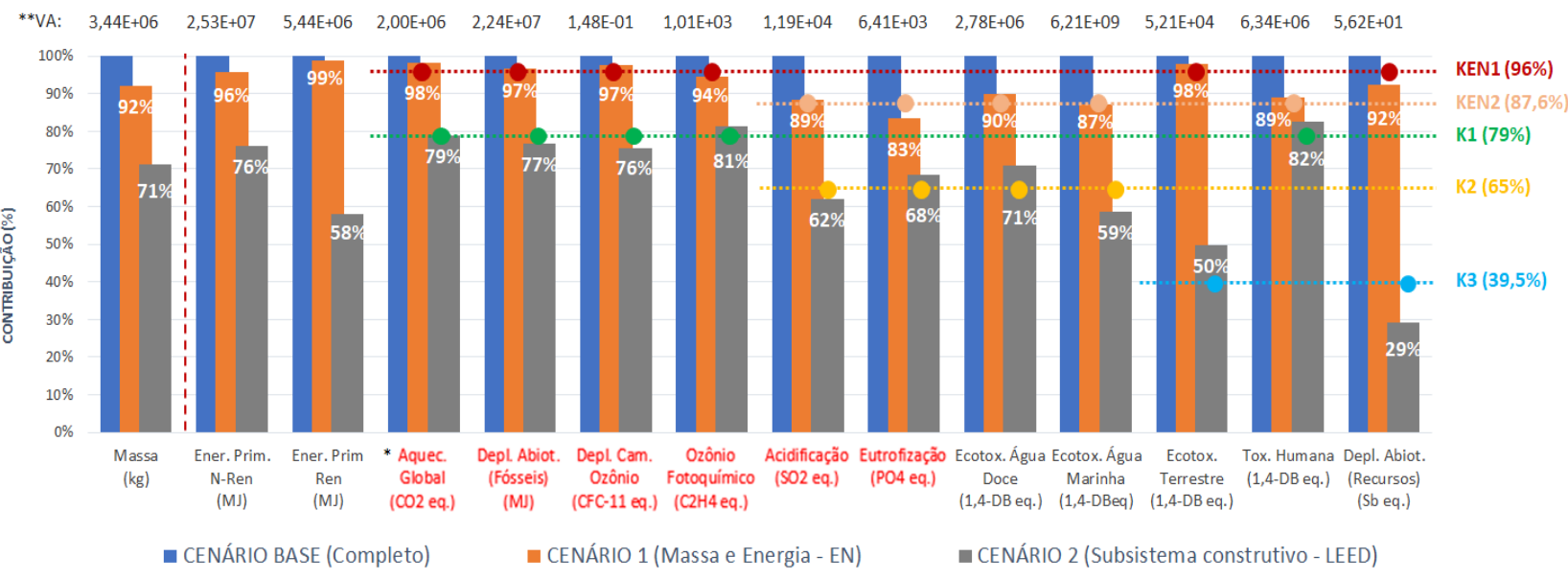

${ }^{*}$ Em destaque vermelho as categorias de impacto consideradas pelo LEED v4

**VA: Valor absoluto

Fonte: as autoras. 
Para o cenário-base, elementos de estrutura e envelope compõem aproximadamente $70 \%$ da massa total do ciclo de vida. Os impactos associados decorrem principalmente do aço presente na estrutura e na vedação externa em painéis sanduíche. Os sistemas prediais (instalações elétricas e dados, hidrossanitárias, e adicionais), com pouco menos de $2 \%$ da massa no ciclo de vida, tiveram maior expressão nas categorias de impacto de eutrofização (19\%), acidificação (14\%), ecotoxicidades aquática (12 a 15\%) e toxicidade humana (12\%), principalmente devido ao cobre utilizado (Figura 8 ). As vedações internas destacaram-se em todas as categorias, mas absolutamente dominaram as categorias do cluster 3: de 48 a 60\% dos impactos em ecotoxicidade terrestre e depleção de recursos abióticos, pois o aço galvanizado nos perfis do sistema de gesso acartonado representou, sozinho, 60\% dos impactos nesta última categoria (Figura 8 e Figura 9). Analisando a edificação como um todo, aços laminado e galvanizado, alumínio e cobre basicamente respondem pelos impactos.

Figura 8 - Estudo B - Impactos (valor absoluto (VA) e contribuições) por subsistema da edificação, para o cenário-base. Em vermelho, as categorias consideradas pelo LEED v4. A linha tracejada destaca a contribuição dos elementos de estrutura e envelope. A contribuição para a massa no ciclo de vida é indicada para referência.

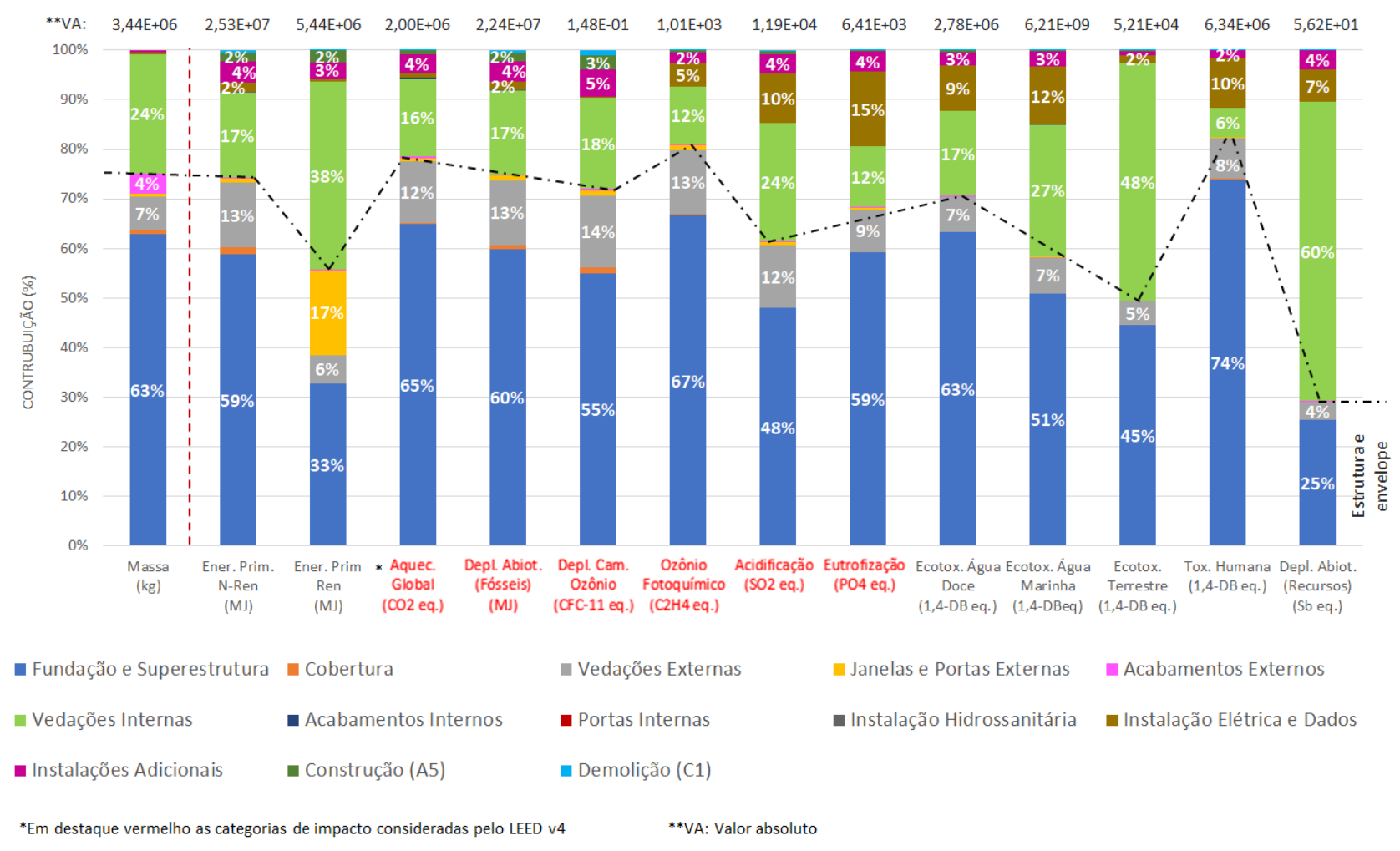

Fonte: as autoras.

\section{Discussão}

Esta investigação confirmou a hipótese de que impactos consideráveis são negligenciados na perspectiva do LEED V4, o que prejudica a compreensão adequada dos resultados da avaliação, relativamente à abordagem das normas europeias.

Quanto à questão de pesquisa 1 - implicações da regra de corte e limitação das categorias de impacto consideradas pela abordagem do LEED v4 - a redução de escopo efetuada para fins de certificação faz com que a avaliação cubra uma parte muito limitada dos impactos da edificação. De um lado, o enfoque no envelope e estrutura presume - a partir de indicações práticas e da literatura - que a distribuição de impactos entre os subsistemas siga proporção semelhante à proporção de massa. No entanto, 
esse princípio é distorcido por elementos com massa proporcionalmente baixa, mas que representam parcela considerável de impactos. É o caso dos plásticos e metais, normalmente presentes nas instalações prediais, que são excluídas do limite de sistema de uma ACVed pelo LEED v4.

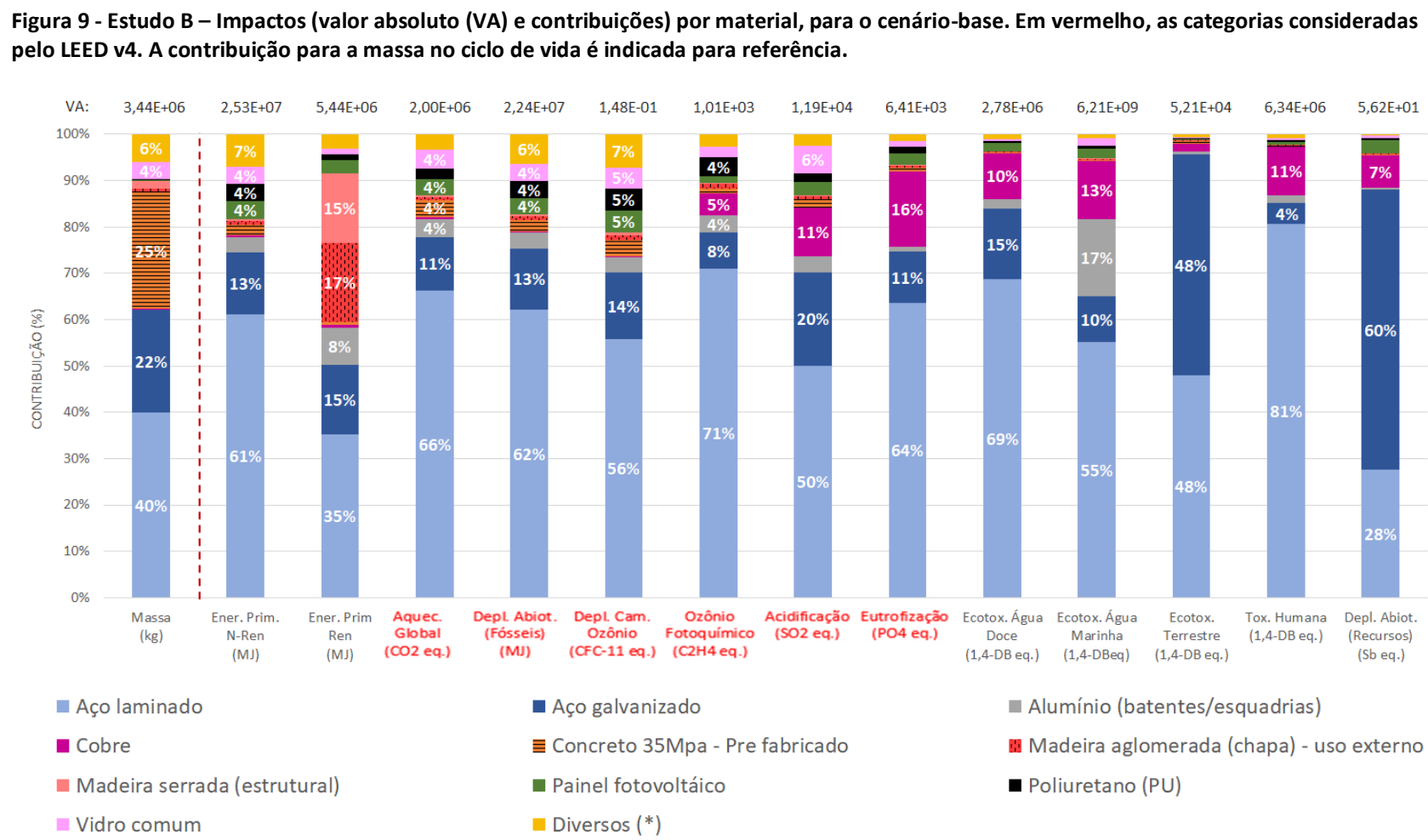

(*) Itens com valores inferiores a 5\% em todas as categorias de impacto: Aço (vergalhões); Concreto permeável; Etileno (tubo); Lã de vidro; Placa de fibra de gesso; Placa de gesso acartonado; Polipropileno (PP); Cloreto de polivinila (PVC); Telhado verde; Tinta betuminosa; Tinta epóxi; Construção (A5); Demolição (C1).

Fonte: as autoras.

De fato, como identificado por Lambertz et al. (2019) para um edifício de escritórios típico na Alemanha, dos $41,6 \%$ dos impactos ambientais associados aos materiais e sistemas da edificação, $23 \%$ correspondiam aos sistemas prediais, mesmo constituindo apenas $0,5 \%$ da massa computada para a edificação. Os demais materiais e sistemas $99,5 \%$ da massa - respondiam por $18,5 \%$ dos impactos totais, e a energia operacional representava os $58,4 \%$ restantes.

Por outro lado, apesar de o LEED elencar seis categorias ambientais, a avaliação de fato considera apenas três, enquanto as normas europeias abrangem categorias nos oito grupos ambientais principais em ACV. Este trabalho investigou apenas dois casos, mas evidenciou que (1) os impactos dos subsistemas excluídos pela regra de corte são mais substanciais em categorias não avaliadas pelo LEED, como ecotoxicidade, toxicidade humana e depleção de recursos abióticos, em que a produção de materiais de construção tem efeito relevante; e (2) a livre escolha de três categorias ambientais permite redundância caso todas elas façam parte de um mesmo cluster e descrevam tendência similar. Portanto, na prática, além de se excluir elementos potencialmente com alto impacto, ainda há a possibilidade de se ignorar as categorias mais afetadas por eles, o que contraria as recomendações e boas práticas de ACVed.

Grupos de categorias que apresentem similaridade e tendências redundantes podem, em tese, ser representados por qualquer uma delas. A conduta do LEED obriga a avaliação de aquecimento global, mas permite que as outras duas categorias sejam escolhidas dentro do mesmo grupo (ex.: depleção abiótica - combustíveis fósseis, e 
depleção da camada de ozônio) e representem redundância, enquanto outras categorias importantes (ecotoxicidade terrestre e depleção de recursos abióticos), considerando os impactos amplamente documentados do setor da construção, ficam a descoberto.

A questão de pesquisa 2 também remete à quantificação da parcela dos impactos ignorada em função da regra de corte do LEED, que é mais substancial em categorias de ecotoxicidade e depleção de recursos abióticos, não avaliadas para fins da certificação e, como mencionado, diretamente associadas aos plásticos e, principalmente, aos metais componentes da edificação. Isto significa que - ao se ater ao leque de categorias hoje considerado pelo LEED v4 - tem-se a impressão que menos impacto deixa de ser capturado ( 33 a $45 \%$ para o Estudo A, e 13 a $27 \%$, para o Estudo B). No entanto, relativamente aos impactos retidos pelas normas europeias, esta parcela chegou a $52 \%$ (EP e FAETP), 59\% (ADPres) e 66\% (TAETP), para o Estudo A. Para o Estudo B, essa diferença foi menor, mais ainda alcançou 27\% (AP), 28\% (FAETP), 48\% (TAETP) e 63\% (ADPres).

Para o Caso A, caso o LEED v4 incluísse os acabamentos internos na ACVed, as faixas de retenção dos impactos aumentariam para $75-80 \%$ (cluster 1 ), cerca de $60 \%$ (cluster 2 ) e 27-58\% (cluster 3). Caso o LEED v4 incluísse instalações elétricas e dados, o efeito seria menor no grupo 1 (+12 a 17\%), mas a abrangência de impactos no grupo $2(+32$ a $38 \%)$ e no grupo $3(+38$ a $71 \%)$ aumentaria consideravelmente, apesar da pequena contribuição em massa ( $8 \%$ ) representada (Figura 4 ).

Para o Caso B, caso o LEED v4 incluísse as vedações internas na ACVed, a contabilização dos impactos aumentaria substancialmente: para 91 a 95\% (cluster 1), 80 a 88\% (cluster 2) e 88 a $97 \%$ (cluster 3). Caso o LEED v4 incluísse instalações elétricas e dados, o acréscimo seria menor no grupo $1(<5 \%)$, mas a abrangência nos grupos 2 e 3 aumentaria entre 3 e 19\%, pela consideração dos impactos associados ao cobre, apesar de sua contribuição em massa ser desprezível (Figura 8).

As características da edificação, em termos da massa de metais fora dos subsistemas considerados pelo LEED (estrutura e envelope), definem quão substancial será o descolamento em relação aos processos retidos pelas normas europeias, e em quais categorias de impacto ele será mais notável.

Os casos analisados configuram diferentes proporções de metais, em massa, e também de distribuição destes metais nos subsistemas das edificações. Exceto pelos acabamentos internos em revestimento cerâmico no estudo A, com efeito importante no uso de recursos minerais (depleção de recursos abióticos), os sistemas excluídos têm, em comum, a contribuição expressiva para a massa de aço e cobre nas respectivas edificações. Ou seja: incluir 1 ou 2 subsistemas (o que contiver mais metais, por exemplo) no LEED v4 já faria muita diferença, não só em termos de abrangência em cada categoria isoladamente, mas do conjunto dos impactos considerados, por sua relação com categorias hoje negligenciadas.

Assim, pode-se conjecturar sobre dois caminhos que melhorariam o significado da ACVed realizada para o LEED v4, relacionados à questão de pesquisa 3 - se haveria evidência de um equilíbrio viável entre um corte mais substancial de processos, que facilite a realização de ACVed, e mantenha a integridade das principais conclusões.

Especificação de regras para adicionar à avaliação subsistemas críticos ou compensar por sua exclusão

A massa de metais na edificação $A$ no estágio de produto ( $A 1-A 3)$ é de apenas $0,7 \%$, mas $78 \%$ dela está nos sistemas prediais e foi excluída da avaliação pelo LEED. Os sistemas e 
redes prediais consistem, em grande parte, de componentes plásticos e metálicos, que frequentemente têm impactos ambientais por unidade de massa, que pode ser várias vezes superior aos de outros materiais de construção. Como exemplos, Lambertz et al. (2019) citam que o potencial de aquecimento global na fase de produção de $1 \mathrm{~kg}$ de tubulação de PE-X-Alu corresponde ao de cerca de $4 \mathrm{~kg}$ de isolamento de espuma rígida de poliestireno utilizada em paredes e coberturas, e ao de cerca de $80 \mathrm{~kg}$ de concreto estrutural. Estes sistemas também possuem menor vida útil o que aumenta a frequência dos ciclos de substituição, de modo que sua contribuição aos impactos é ainda maior na etapa de uso e operação.

Já o Estudo $B$ tem uma quantidade de metais por unidade de área mais de seis vezes maior que o Estudo A. Quase $60 \%$ da massa da edificação no estágio de produto é formada por metais, mas - por ter estrutura e vedações externas em aço - apenas $23 \%$ seriam excluídos da ACVed pelo LEED, correspondendo principalmente aos perfis de aço galvanizado das divisórias internas. Estes achados iniciados pelos dois casos estudados sugerem que, para edificações com alta parcela de metais - digamos, acima de $25 \%$ - fora dos subsistemas estrutura e envelope, os subsistemas concentrando metais devam necessariamente compor a avaliação da edificação - digamos, até cobrir pelo menos $75 \%$ dos metais - para aumentar a retenção de processos e fornecer uma melhor descrição dos impactos ambientais no ciclo de vida.

Alternativamente, para, de alguma forma, considerar as instalações e seus efeitos ambientais, sem aumentar demasiadamente o trabalho vinculado à ACVed, o LEED poderia adotar um "fator de sistemas prediais" que assuma determinada massa de (metais nas) instalações por unidade de área construída. Um artifício semelhante é utilizado pela certificação DGNB ao se optar pela versão simplificada da contabilização de sistemas prediais: um fator majora os impactos das instalações e economiza trabalho de levantamento dos quantitativos, ainda que Lambertz et al. (2019) sugiram que este fator devesse ser superior aos $20 \%$ genericamente adotados pela avaliação alemã.

Especificação das categorias a avaliar, em vez de indicar elegibilidade, incluindo aquelas que fornecessem um espectro de impactos ambientais mais completo

Para os dois casos estudados, categorias ambientais mantiveram similaridade dentro de três grupos nas ACVed segundo o LEED: [GWP, ADPff, ODP], [EP, FAETP, MAETP] e [TAETP, ADres]. Dentro de cada grupo, em princípio, quaisquer das categorias seria suficientemente similar para descrever a tendência das demais.

É consensual a preocupação com mudança climática (GWP), que apresentou similaridade com depleção abiótica de recursos fósseis (ADPff) e com depleção da camada de ozônio (ODP). Potencial de eutrofização (EP) já está entre as seis categorias elegíveis e teve similaridade com ecotoxicidade de águas doce (FAETP) e marinha (MAETP). Uma possibilidade de ajuste do LEED poderia ser, em vez de permitir uma seleção aleatória de categorias que poderiam descrever resultados redundantes, incluir a categoria de depleção abiótica de recursos (ADPres), de modo que estes três clusters estariam representados na avaliação. Caso a conduta mudasse para efetivamente definir obrigatoriedade de se avaliar categorias específicas, a consideração conjunta de GWP, EP, ADPres - cada uma representando os clusters observados - mais as categorias AP, PCOP e HTP - que não apresentaram um padrão consistente de similaridade para os casos estudados - forneceria um espectro de impactos ambientais muito mais completo.

Lasvaux et al. (2016) demonstraram estatisticamente que os conjuntos de indicadores ambientais têm dimensionalidade entre 4 e 6 , o que significa que todos os indicadores são fortemente correlacionados a 4 a 6 componentes (dimensões), que ditam mais de 
90\% da variância total para cada indicador ambiental, independentemente do método AICV. Lasvaux et al. (2016) encontraram quatro componentes (clusters) para as categorias do $C M L$, dos quais três seriam preservados na versão baseline: [ADPres, GWP, PCOP, AP, EP], [FAETP, HTP, MAETP, TAETP], [ODP]. Essa clusterização em si difere daquela observada para os casos alvo deste artigo, mas alinha-se com nossos achados ao apontar potenciais redundâncias como frente de simplificação para que se possa cobrir outras categorias relevantes e descorrelacionadas, nomeadamente ecotoxicidade e depleção da camada de ozônio.

\section{Conclusão}

As regras de corte abordadas neste estudo apresentam diferentes oportunidades para reduzir os esforços para desenvolvimento dos inventários e promover o uso da ACV em edificações como método de avaliação de desempenho ambiental. O corte por massa e energia retém mais fluxos nos diferentes subsistemas construtivos em todas as etapas do ciclo de vida da edificação. Para aplicar esta regra é preciso ter conhecimento do total de massa e de energia, o que é mais trabalhoso, mas numa tarefa que tende a ser simplificada, conforme o avaliador ganha experiência. Dito isso, a abrangência dos impactos é notável, relativamente à retenção alcançada com aplicação do corte de inventário segundo a abordagem LEED.

O conservadorismo da regra de corte da norma europeia retém fluxos em diferentes subsistemas construtivos, preservando elementos que tendem a maior número de substituições ao longo da vida útil da edificação, e, portanto, captura maior parcela de impactos associados (acima de $80 \%$ ) e de massa total do ciclo de vida (acima de $90 \%$ ).

Considerar apenas elementos da estrutura e envelope sem dúvida traz praticidade à modelagem praticada pelo LEED v4, mas a um preço alto de completeza que, sim, compromete a interpretação: para os casos estudados, $70 \%$ da massa total no ciclo de vida foi retida, mas que se traduzem em apenas $20 \%$ a $70 \%$ dos impactos ambientais relativamente ao cenário base.

A redução de escopo efetuada para fins de certificação LEED cobre uma parte muito limitada dos impactos da edificação. Ao reter apenas os processos no envelope e estrutura, exclui-se do limite de sistema de uma ACVed pelo LEED v4 materiais com alto impacto por unidade de massa, como plásticos e metais, normalmente presentes nas instalações prediais, que também estão sujeitos a ciclos mais curtos de substituição.

A parcela dos impactos ignorada em função da regra de corte do LEED é mais substancial em categorias de ecotoxicidade e depleção de recursos abióticos, não avaliadas para fins da certificação. Com o atual enfoque nas categorias consideradas pelo LEED v4, tem-se a impressão que menos impacto deixa de ser capturado.

Uma vez que o principal público das certificações ambientais são edifícios de escritórios, que normalmente apresentam maior intensidade de sistemas prediais do que outras tipologias, para equilibrar um corte mais substancial de processos, que facilite a realização de ACVed, enquanto assegura a integridade das principais conclusões, recomendamos que a certificação revise sua avaliação para (1) incluir subsistemas na avaliação até computar parcela significativa ( $75 \%$ ) dos metais, ou adotar um índice para representar - ainda que parcialmente - esses impactos, e (2) ampliar estrategicamente o conjunto de categorias ambientais avaliadas, o que aumentará a robustez dos resultados utilizados para informar a tomada de decisões. 
Naturalmente, estas observações, feitas à luz de apenas dois casos, precisam ser confirmadas em mais estudos, já em andamento, para identificar padrões e gradativamente popular um banco de referências de desempenho (benchmarks).

\section{Agradecimentos}

O presente trabalho foi realizado com apoio da Coordenação de Aperfeiçoamento de Pessoal de Nível Superior Brasil (CAPES) - Código de Financiamento 001 (Processo \# 88887.480078/2020-00), e do CNPq (Processo \# 306048/2018-3).

\section{Referências}

ABNT - ASSOCIAÇÃO BRASILEIRA DE NORMAS TÉCNICAS. NBR 15575-1: Edificações Habitacionais - Desempenho Parte 1: Requisitos gerais Prefácio. Rio de Janeiro: 2013.

ACERO, A.; RODRIGUEZ, C.; CIROTH, A. LCIA methods Impact assessment methods in Life Cycle Assessment and their impact categories, v1.5.4. Open LCA Report, 23p, 2015.

BRASIL. Ministério da Educação. Fundo Nacional de Desenvolvimento da Educação. Projeto Espaço Educativo Urbano e Rural - 6 salas. Revisão 2015. Disponível em: https://www.fnde.gov.br/programas/par/eixos-deatuacao/infraestrutura-fisica-escolar. Acesso em: 08 ago. 2020.

CEN -EUROPEAN COMMITTEE FOR STANDARDIZATION. EN 15804 - Sustainability of construction works Environmental product declarations - Core rules for the product category of construction products. [s.l.] British Standards Institution, 2012.

CEN - EUROPEAN COMMITTEE FOR STANDARDIZATION. EN 15978 - Sustainability of construction works Assessment of environmental performance of buildings - Calculation method. [s.l.] British Standards Institution, 2011.

DOBBELSTEEN, A.A.J.F.; ARETS, M.; NUNES, R. Sustainable design of supporting structures. Optimal structural spans and component combinations for effective improvement of environmental performance. Construction Innovation, v.7, n. 1, p. 54-71, Emerald Group Publishing, 2007.

EC JRC-IES. International Reference Life Cycle Data System (ILCD) Handbook - general guide for life cycle assessment - detailed guidance. First ed. Luxembourg: Publications Office of the European Union, 2010.

EEBGUIDE PROJECT. EeBGuide Guidance Document - Part B: Buildings - Operational Guidance for Life Cycle Assessment Studies of the Energy Efficient Buildings Initiative. Disponível em: www.eebguide.eu, 2012. Acesso em: 14 jun. 2019.

GOMES, V. et al. Exploring lifecycle energy and greenhouse gas emissions of a case study with ambitious energy compensation goals in a cooling-dominated climate. Energy and Buildings, v. 173, p. 302-314, ago. 2018a. DOI: https://doi.org/10.1016/j.enbuild.2018.04.063.

GOMES, V. et al. LEED v4 approach to LCA at whole-building Level. In: CONGRESSO BRASILEIRO SOBRE GESTÃO DO CICLO DE VIDA, 6., Brasília, 2018. Anais [...]. Brasília: IBICT e ABCV, 2018b.

HAAPIO, A.; VIITANIEMI, P. Environmental effect of structural solutions and building materials to a building. Environmental Impact Assessment Review, v.28, n.8, p.587-600, 2008. DOI:

https://doi.org/10.1016/j.eiar.2008.02.002 .

IEA - INTERNATIONAL ENERGY AGENCY. Evaluation of embodied energy and CO2eq for building construction (Annex 57) - Overview of Annex 57 results. Energy in Buildings and Communities (EBC) Programme. September 2016. 100 p. Disponível em: http://www.annex57.org/wp/wp-content/uploads/2017/05/Overview-Report.pdf. Acesso em: 08 ago. 2020. 
ISO - INTERNATIONAL STANDARD ORGANIZATION. ISO 14040 - Environmental management - Life cycle assessment - Principles and framework. Switzerland: ISO, 2006a.

ISO - INTERNATIONAL STANDARD ORGANIZATION. ISO 14044 - Environmental management - Life cycle assessment - Requirements and guidelines. Switzerland: ISO, 2006b.

ISMAEEL, W. S. E. Midpoint and endpoint impact categories in Green building rating systems. Journal of Cleaner Production, v. 182, p. 783-793, 1 maio 2018. DOI: http://dx.doi.org/10.1016/j.jclepro.2018.01.217 .

KELLENBERGER, D.; ALTHAUS, H. Relevance of simplifications in LCA of building components. Building and Environment, v. 44, n. 4, p. 818-25, 2009. DOI: https://doi.org/10.1016/j.buildenv.2008.06.002 .

LAMBERTZ, M. et al. Importance of building services in ecological building assessments. E3S Web of Conferences, v. 111, n. 03061, 2019. DOI: https://doi.org/10.1051/e3sconf/201911103061 .

LASVAUX, S. et al. Correlations in Life Cycle Impact Assessment methods (LCIA) and indicators for construction materials: What matters? Ecological Indicators, v. 67, p. 174-182, ago. 2016. DOI:

https://doi.org/10.1016/j.ecolind.2016.01.056 .

LESSARD, Y. et al. LEED v4: Where Are We Now? Critical Assessment through the LCA of an Office Building Using a Low Impact Energy Consumption Mix. Journal of Industrial Ecology, v. 00, n. 0, p. 1-12, 5 set. 2017. DOI: https://doi.org/10.1111/jiec.12647 .

MOON, K. S. Sustainable design of tall building structures and façades. In: CIB INTERNATIONAL CONFERENCE ON SMART AND SUSTAINABLE BUILT ENVIRONMENT, 3., 2009, Delft. Proceedings [... ]. The Netherlands: CIB, v.1, p.1-8, 2009.

MORALES, M. et al. Regionalized inventory data in LCA of public housing: A comparison between two conventional typologies in southern Brazil. Journal of Cleaner Production, v. 238, 2019. DOI:

https://doi.org/10.1016/j.jclepro.2019.117869 .

PINI. TCPO - Tabela de Composições de Preços para Orçamentos - Engenharia Civil, Construção e Arquitetura. $13 a$ ed. São Paulo: Pini, 2008.

PULGROSSI, Lizzie Monique. Influência das regras de corte nos resultados de avaliação do ciclo de vida de edificações completas. 2020. 113 f. Dissertação (Mestrado) - Programa de Pós-Graduação em Arquitetura, Tecnologia e Cidade, Faculdade de Engenharia Civil, Arquitetura e Urbanismo, Universidade Estadual de Campinas, Campinas, 2020.

SAADE, M.R.M.; SILVA, M. G.; GOMES, V. A Avaliação do Ciclo de Vida (ACV) e a etapa de avaliação de impactos ambientais: considerações sobre o uso de diferentes métodos e seus reflexos nos resultados finais. Natureza On Line, Espírito Santo, v. 13, p. 109-116, 2014. Disponível em:

http://www.naturezaonline.com.br/natureza/conteudo/pdf/02_SaadeMRMetal_109-116.pdf. Acesso em: 15 ago. 2020.

PRé. SimaPro Database Manual Methods Library. Report v4.15. June 2020. 74 p.

SOUST-VERDAGUER, B.; LLATAS, C.; GARCÍA-MARTÍNEZ, A. Simplification in life cycle assessment of single-family houses: A review of recent developments. Building and Environment, v. 103, p. 215-227, 1 jul. 2016. DOI: http://dx.doi.org/10.1016/j.buildenv.2016.04.014 .

TODD, J. A. Buildings, Systems Thinking, and Life Cycle Assessment. In: CURRAN, M. A. (Ed.). Life Cycle Assessment Handbook: A Guide for Environmentally Sustainable Products. Salem, MA, USA: Scrivener Publishing LLC, 2012. p. 311-328. DOI: https://doi.org/10.1002/9781118528372.ch14 . 
USGBC -U.S. GREEN BUILDING COUNCIL. LEED Reference Guide for Building Design and Construction. Washington D.C., 2013. Disponível em: https://www.usgbc.org/resources/leed-v4-building-design-and-construction-currentversion. Acesso em: 06 mar. 2019.

\section{Apêndice A - Detalhamento do inventário dos estudos de caso}

\begin{tabular}{|c|c|c|c|c|}
\hline \multirow{2}{*}{$\begin{array}{c}\text { Caso A - Edifício escolar - Inventário completo } \\
\text { Processo Produtivo - base de dados Ecoinvent v3.4/3.5 }\end{array}$} & \multicolumn{4}{|c|}{ Massa $(\mathrm{kg})$ por estágio $\mathrm{ACV}$} \\
\hline & A1-3 & A4-5 & B4 & C1-4 \\
\hline Acrylonitrile-butadiene-styrene copolymer $\{$ RoW $\} \mid$ production | Cut-off, U & 15,01 & 1,50 & 240,16 & 16,51 \\
\hline Adhesive mortar $\{$ RoW $\} \mid$ production | Cut-off, $U$ & $6.740,10$ & 134,80 & $20.220,29$ & $6.874,90$ \\
\hline $\begin{array}{l}\text { Alkyd paint, white, without solvent, in } 60 \% \text { solution state }\{\text { RoW }\} \mid \text { alkyd paint } \\
\text { production, white, solvent-based, product in } 60 \% \text { solution state | Cut-off, } U\end{array}$ & 37,42 & 3,37 & 393,65 & 40,79 \\
\hline $\begin{array}{l}\text { Alkyd paint, white, without water, in } 60 \% \text { solution state }\{\text { RoW\}| alkyd paint } \\
\text { production, white, water-based, product in } 60 \% \text { solution state | Cut-off, } U\end{array}$ & 331,20 & 29,81 & $3.693,07$ & 361,00 \\
\hline Aluminium alloy, AIMg3 $\{$ RoW\}| production | Cut-off, U & 213,50 & 27,76 & $3.416,00$ & 241,26 \\
\hline Aluminium, wrought alloy $\{$ GLO $\} \mid$ market for | Cut-off, $U$ & 32,89 & 4,28 & 394,68 & 37,17 \\
\hline Bitumen adhesive compound, cold $\{$ RoW $\} \mid$ production | Cut-off, $U$ & 208,57 & 20,86 & 0,00 & 229,42 \\
\hline Brass $\{$ RoW $\} \mid$ production | Cut-off, $U$ & 17,90 & 2,33 & 286,46 & 20,23 \\
\hline Cable, three-conductor cable $\{$ GLO $\} \mid$ production | Cut-off, $U$ & 537,55 & 10,75 & $1.075,10$ & 548,30 \\
\hline Cast iron $\{$ RoW $\} \mid$ production | Cut-off, $U$ & $4.606,15$ & 598,80 & $29.386,30$ & $5.204,95$ \\
\hline $\begin{array}{l}\text { Cast iron }\{\text { RoW }\} \mid \text { production | Cut-off, } U+\text { Zinc coat, coils }\{\text { RoW }\} \mid \text { zinc coating, } \\
\text { coils | Cut-off, } U\end{array}$ & 14,72 & 1,91 & 29,44 & 16,63 \\
\hline Casting, bronze $\{$ RoW $\} \mid$ processing | Cut-off, $U$ & 1,35 & 0,18 & 4,06 & 1,53 \\
\hline Cement mortar $\{$ RoW $\} \mid$ production | Cut-off, $U$ & $193.190,21$ & $57.957,06$ & $570.268,14$ & $251.147,27$ \\
\hline Ceramic tile $\{$ RoW $\} \mid$ production | Cut-off, $U$ & $120.102,10$ & $22.819,40$ & $360.306,29$ & $142.921,49$ \\
\hline Clay brick $\{$ RoW $\} \mid$ production | Cut-off, $U$ & $98.419,76$ & $4.920,99$ & $123.704,00$ & $103.340,75$ \\
\hline Concrete block $\{$ RoW $\} \mid$ production | Cut-off, $U$ & 575,10 & 17,25 & $1.150,20$ & 592,35 \\
\hline $\begin{array}{l}\text { Concrete production, } 25 \mathrm{MPa} \text {, ready-mix, with cement blast furnace slag 35- } \\
\text { 70\%_3.6_mfor_BR }\end{array}$ & $3.626 .754,96$ & $181.337,75$ & $307.415,08$ & $3.808 .092,71$ \\
\hline Copper $\{$ RoW $\} \mid$ production, primary | Cut-off, U & 402,86 & 40,29 & $1.208,59$ & 443,15 \\
\hline Epoxy resin, liquid $\{$ RoW $\} \mid$ production | Cut-off, $U$ & 7,60 & 0,38 & 45,61 & 7,98 \\
\hline Flat glass, uncoated $\{$ RoW $\} \mid$ production | Cut-off, $U$ & $1.501,70$ & 150,17 & $3.286,90$ & $1.651,87$ \\
\hline Gravel, round $\{$ RoW $\} \mid$ gravel and sand quarry operation | Cut-off, $U$ & $46.501,80$ & $4.650,18$ & $139.505,40$ & $51.151,98$ \\
\hline Lean concrete $\{$ RoW $\} \mid$ production, with cement CEM II/A | Cut-off, U & $209.493,11$ & $10.474,66$ & $625.070,97$ & $219.967,76$ \\
\hline Lime mortar $\{$ RoW $\} \mid$ production | Cut-off, $U$ & $246.553,04$ & $73.965,91$ & $650.213,44$ & $320.518,96$ \\
\hline Natural stone plate, polished $\{$ RoW $\} \mid$ production | Cut-off, $U$ & $2.394,48$ & 239,45 & $26.379,16$ & $2.633,93$ \\
\hline Nylon 6-6 \{RoW\}| production | Cut-off, U & 0,67 & 0,07 & 8,06 & 0,74 \\
\hline Plywood, for indoor use $\{$ RoW\}| production | Cut-off, U & 870,48 & 87,05 & $7.250,88$ & 957,53 \\
\hline Polyethylene, high density, granulate $\{$ RoW $\} \mid$ production | Cut-off, $U$ & 0,29 & 0,03 & 4,61 & 0,32 \\
\hline Polypropylene, granulate $\{$ RoW $\} \mid$ production | Cut-off, $U$ & 37,62 & 3,76 & 112,86 & 41,38 \\
\hline $\begin{array}{c}\text { Polyvinylchloride, suspension polymerised }\{\text { RoW }\} \mid \text { polyvinylchloride } \\
\text { production, suspension polymerisation | Cut-off, } U\end{array}$ & $3.856,89$ & 578,53 & $7.714,43$ & $4.435,42$ \\
\hline Reinforcing Steel $\{$ RoW $\} \mid$ production | Cut-off, U & $7.729,93$ & 772,99 & $3.122,19$ & $8.502,92$ \\
\hline Sanitary ceramics $\{$ RoW $\} \mid$ production | Cut-off, $U$ & 234,40 & 23,44 & $3.750,40$ & 257,84 \\
\hline Sawnwood, softwood, dried (u=10\%), planed $\{$ RoW\}| production | Cut-off, U & $24.819,18$ & $2.481,92$ & $49.638,36$ & $27.301,10$ \\
\hline Sheet rolling, aluminium $\{$ RoW $\} \mid$ processing | Cut-off, $U$ & 49,22 & 6,40 & 199,12 & 55,62 \\
\hline $\begin{array}{c}\text { Steel, chromium steel } 18 / 8\{\text { RoW }\} \text { steel production, electric, chromium steel } \\
18 / 8 \mid \text { Cut-off, } U\end{array}$ & 472,95 & 61,48 & $2.462,11$ & 534,44 \\
\hline Steel, low-alloyed $\{$ RoW\}| steel production, electric, low-alloyed | Cut-off, U & $17.540,34$ & $2.280,24$ & $105.176,47$ & $19.820,59$ \\
\hline $\begin{array}{l}\text { Steel, low-alloyed }\{\text { RoW }\} \mid \text { steel production, electric, low-alloyed | Cut-off, U + } \\
\text { Zinc coat, coils }\{\text { RoW }\} \mid \text { zinc coating, coils | Cut-off, } U\end{array}$ & 13,75 & 1,79 & 27,51 & 15,54 \\
\hline Synthetic rubber $\{$ RoW $\} \mid$ production | Cut-off, $U$ & 204,75 & 4,10 & $1.228,50$ & 208,85 \\
\hline Vinyl acetate $\{$ RoW $\} \mid$ production | Cut-off, $U$ & 609,32 & 60,93 & $1.834,11$ & 670,25 \\
\hline Window frame, aluminium, $\mathrm{U}=1.6 \mathrm{~W} / \mathrm{m} 2 \mathrm{~K}\{\mathrm{RoW}\} \mid$ production | Cut-off, $\mathrm{U}$ & 263,62 & 34,27 & 527,24 & 297,89 \\
\hline Window frame, wood, $\mathrm{U}=1.5 \mathrm{~W} / \mathrm{m} 2 \mathrm{~K}\{$ RoW $\} \mid$ production | Cut-off, $\mathrm{U}$ & 427,65 & 42,77 & $2.565,91$ & 470,42 \\
\hline SOMA TOTAL & $4.615 .784,14$ & $363.849,58$ & $3.053 .315,74$ & $4.979 .633,73$ \\
\hline
\end{tabular}

Fonte: as autoras. 
PULGROSSI, Lizzie Monique; SILVA, Vanessa Gomes da

Influência de regras de corte de inventário nos resultados de ACV de edificações

Tabela A2 - Metais das instalações prediais do caso A - Edifício escolar

Caso A - Edifício escolar - Metais das Instalações prediais (Elétrica e dados, Hidrossanitário, Adicionais)

Processo Produtivo - base de dados Ecoinvent v3.4/3.5

Aluminium alloy, AlMg3 $\{$ RoW $\}$ | production | Cut-off, $U$ Brass $\{$ RoW $\} \mid$ production | Cut-off, $U$

Cable, three-conductor cable $\{$ GLO $\}$ | production | Cut-off, $U$ Cast iron $\{$ RoW $\} \mid$ production | Cut-off, $U$

Cast iron $\{$ RoW $\} \mid$ production | Cut-off, $U+$ Zinc coat, coils $\{$ RoW $\} \mid$ zinc coating, coils | Cut-off, $U$

Casting, bronze $\{$ RoW $\} \mid$ processing | Cut-off, $U$

Copper $\{$ RoW $\} \mid$ production, primary | Cut-off, $U$

Reinforcing Steel $\{$ RoW $\} \mid$ production | Cut-off, $U$

Sheet rolling, aluminium $\{$ RoW $\} \mid$ processing | Cut-off, $U$

Steel, chromium steel $18 / 8\{$ RoW $\} \mid$ steel production, electric, chromium steel $18 / 8$ | Cut-off, $U$

\begin{tabular}{cccc} 
& & \\
& & & \\
A $1-3$ & $\mathrm{~A} 4-5$ & $\mathrm{~kg}$ ) por estágio ACV & \\
\hline 213,50 & 27,76 & $3.416,00$ & 241,26 \\
\hline 17,90 & 2,33 & 286,46 & 20,23 \\
\hline 537,55 & 10,75 & $1.075,10$ & 548,30 \\
\hline $4.606,15$ & 598,80 & $29.386,30$ & $5.204,95$ \\
\hline 14,72 & 1,91 & 29,44 & 16,63 \\
\hline 1,35 & 0,18 & 4,06 & 1,53 \\
\hline 402,86 & 40,29 & $1.208,59$ & 443,15 \\
\hline 974,73 & 97,47 & $2.897,15$ & $1.072,21$ \\
\hline 0,16 & 0,02 & 2,59 & 0,18 \\
\hline 108,30 & 14,08 & $1.732,80$ & 122,38 \\
\hline $17.540,34$ & $2.280,24$ & $105.176,47$ & $19.820,59$ \\
\hline 13,75 & 1,79 & 27,51 & 15,54 \\
\hline $24.431,33$ & $3.075,61$ & $145.242,47$ & $27.506,95$ \\
\hline
\end{tabular}

Fonte: as autoras.

\begin{tabular}{cccc} 
Steel, low-alloyed $\{$ RoW\}| steel production, electric, low-alloyed | Cut-off, U & $17.540,34$ & $2.280,24$ & $105.176,47$ \\
\hline $\begin{array}{c}\text { Steel, low-alloyed }\{\text { RoW\}| steel production, electric, low-alloyed | Cut-off, U } \\
+ \text { Zinc coat, coils }\{\text { RoW\}| zinc coating, coils | Cut-off, U }\end{array}$ & 13,75 & 1,79 & 27,51 \\
\hline SOMA TOTAL & $24.431,33$ & $3.075,61$ & 145,54 \\
\hline
\end{tabular}

$$
\text { SOMA TOTAL }
$$

Tabela A3 - Inventário completo do caso B - Laboratório

\section{Caso B - Laboratório - Inventário completo}

Processo Produtivo - base de dados Ecoinvent v3.4/3.5

Bitumen adhesive compound, cold $\{$ RoW $\}$ | production | Cut-off, $U$

$\begin{array}{ccc} & \text { Massa }(\mathrm{kg}) \text { por estágio ACV } \\ \mathrm{A} 1-3 & \mathrm{~A} 4-5 & \mathrm{~B} 4\end{array}$

\begin{tabular}{|c|c|c|c|}
\hline A1-3 & A4-5 & B4 & C1-4 \\
\hline $2.074,49$ & 207,45 & $4.148,98$ & $2.281,94$ \\
\hline $398.406,90$ & $35.856,62$ & 0,00 & $434.263,52$ \\
\hline 770,04 & 77,00 & $1.455,25$ & 847,04 \\
\hline 272,39 & 13,62 & 817,16 & 286,00 \\
\hline $1.045,90$ & 104,59 & $2.091,79$ & $1.150,48$ \\
\hline $38.159,52$ & $3.815,95$ & $38.159,52$ & $41.975,47$ \\
\hline $179.671,14$ & $23.357,25$ & $357.670,07$ & $203.028,39$ \\
\hline 202,54 & 20,25 & 202,54 & 222,79 \\
\hline $5.904,70$ & 590,47 & $5.904,70$ & $6.495,17$ \\
\hline 168,60 & 16,86 & 337,20 & 185,46 \\
\hline $1.629,84$ & 162,98 & $3.259,68$ & $1.792,82$ \\
\hline $67.133,77$ & $3.356,69$ & 0,00 & $70.490,46$ \\
\hline $2.674,40$ & 0,00 & $2.674,40$ & $2.674,40$ \\
\hline $5.356,85$ & 535,68 & $10.713,70$ & $5.892,53$ \\
\hline 1,65 & 0,17 & 3,30 & 1,82 \\
\hline $3.731,03$ & 373,10 & $3.731,03$ & $4.104,13$ \\
\hline $1.005,20$ & 150,78 & $2.003,96$ & $1.155,98$ \\
\hline $13.277,93$ & $1.327,79$ & $26.555,86$ & $14.605,72$ \\
\hline $593.316,85$ & $77.131,19$ & $30.547,81$ & $670.448,04$ \\
\hline $9.519,82$ & 951,98 & 0,00 & $10.471,80$ \\
\hline 786,72 & 102,27 & $1.573,43$ & 888,99 \\
\hline $1.325 .110,27$ & $148.152,71$ & $491.850,36$ & $1.473 .262,98$ \\
\hline
\end{tabular}

Copper $\{$ RoW $\} \mid$ production, primary | Cut-off, $U$

Epoxy resin, liquid $\{$ RoW $\} \mid$ production | Cut-off, $U$

Ethylene, pipeline system $\{$ RoW $\}$ | production | Cut-off, $U$

Flat glass, uncoated $\{$ RoW $\} \mid$ production | Cut-off, $U$

Steel, low-alloyed $\{$ RoW $\} \mid$ steel production, electric, low-alloyed | Cut-off, U +

Zinc coat, coils $\{$ RoW $\} \mid$ zinc coating, coils | Cut-off, $U$

Glass wool mat $\{$ RoW $\}$ | production | Cut-off, $U$

Green roof (excluding concrete deck) (US)

Gypsum fibreboard \{RoW\}| production | Cut-off, $U$

Gypsum plasterboard \{RoW\}| production | Cut-off, $U$

Pervious concrete (mix design from Putman (2011))

Photovoltaic panel, single-Si wafer $\{$ RoW $\} \mid$ production | Cut-off, $U$

Plywood, for outdoor use $\{$ RoW $\} \mid$ production | Cut-off, $U$

Polypropylene, granulate $\{$ RoW $\} \mid$ production | Cut-off, $U$

Polyurethane, rigid foam $\{$ RoW $\} \mid$ production | Cut-off, $U$

(20)

nylchloride, suspension polymerised $\{$ RoW $\} \mid$ polyvinylchloride

production, suspension polymerisation | Cut-off, $U$

Sawnwood, softwood, dried ( $\mathrm{u}=10 \%$ ), planed $\{$ RoW $\} \mid$ production | Cut-off, $U$

Steel, low-alloyed, hot rolled $\{$ RoW $\} \mid$ production | Cut-off, $U$ Reinforcing Steel $\{$ RoW $\} \mid$ production | Cut-off, $U$

Window frame, aluminium, $\mathrm{U}=1.6 \mathrm{~W} / \mathrm{m} 2 \mathrm{~K}\{$ RoW $\}$ | production | Cut-off, $\mathrm{U}$ SOMA TOTAL

$1.325 .110,2$

Tabela A4 - Metais das instalações prediais do caso B - Laboratório

Caso B - Laboratório - Metais das Instalações prediais (Elétrica e dados, Hidrossanitário, Adicionais)

Processo Produtivo - base de dados Ecoinvent v3.4/3.5

Copper $\{$ RoW $\} \mid$ production, primary | Cut-off, U_BR_ANNEX_72

Steel, low-alloyed $\{$ RoW $\} \mid$ steel production, electric, low-alloyed | Cut-off, U +

Zinc coat, coils $\{$ RoW $\} \mid$ zinc coating, coils | Cut-off, U_BR_ANNEX_72 SOMA TOTAL

Massa (kg) por estágio ACV

A1-3

770,04

$1.809,73$

A4-5

B4 $1.455,25$

C1-4

$\begin{array}{llll}1.809,73 & 235,27 & 1.947,25 & 2.045,00\end{array}$

$2.579,77$

312,27

$3.402,50$

Fonte: as autoras.

\section{' Lizzie Monique Pulgrossi}

Arquiteta e urbanista. Mestra. Doutoranda do Programa de Pós-Graduação em Arquitetura, Tecnologia e Cidade da 
PULGROSSI, Lizzie Monique; SILVA, Vanessa Gomes da

Influência de regras de corte de inventário nos resultados de ACV de edificações

Faculdade de Engenharia Civil, Arquitetura e Urbanismo. Universidade Estadual de Campinas. Endereço postal: Av. Albert Einstein, 951, Cidade Universitária, Campinas, SP, CEP 13083-852

\section{ii Vanessa Gomes da Silva}

Arquiteta e urbanista. Doutora pela Escola Politécnica da USP em engenharia de construção civil e urbana. Professora livre docente do Departamento de Arquitetura e Construção da Faculdade de Engenharia Civil, Arquitetura e Urbanismo. Universidade Estadual de Campinas. Endereço postal: Av. Albert Einstein, 951, Cidade Universitária, Campinas, SP, CEP 13083-852 